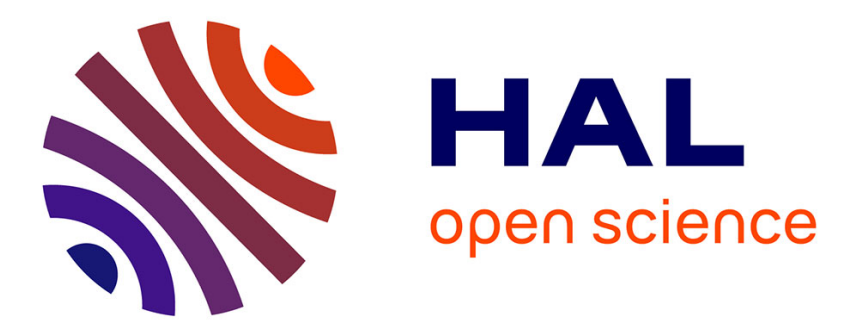

\title{
Induced polarization response of porous media with metallic particles - Part 7: Detection and quantification of buried slag heaps
}

Youzheng Qi, Abdellahi Soueid, André Revil, Ahmad Ghorbani, Feras

Abdulsamad, Nicolas Florsch, Jérémy Bonnenfant, Abdellahi Soueid Ahmed

\section{To cite this version:}

Youzheng Qi, Abdellahi Soueid, André Revil, Ahmad Ghorbani, Feras Abdulsamad, et al.. Induced polarization response of porous media with metallic particles - Part 7: Detection and quantification of buried slag heaps. Geophysics, 2018, 83 (5), pp.E277-E291. 10.1190/GEO2017-0760.1 . hal02324277

\section{HAL Id: hal-02324277 \\ https://hal.science/hal-02324277}

Submitted on 23 Nov 2020

HAL is a multi-disciplinary open access archive for the deposit and dissemination of scientific research documents, whether they are published or not. The documents may come from teaching and research institutions in France or abroad, or from public or private research centers.
L'archive ouverte pluridisciplinaire HAL, est destinée au dépôt et à la diffusion de documents scientifiques de niveau recherche, publiés ou non, émanant des établissements d'enseignement et de recherche français ou étrangers, des laboratoires publics ou privés. 


\title{
Induced polarization response of porous media with metallic particles Part 7: Detection and quantification of buried slag heaps
}

\author{
Youzheng $\mathrm{Qi}^{1}$, Abdellahi Soueid Ahmed ${ }^{1}$, André Revil ${ }^{1}$, Ahmad Ghorbani ${ }^{2}$, Feras Abdulsamad $^{3}$, \\ Nicolas Florsch ${ }^{3}$, and Jeremy Bonnenfant ${ }^{4}$
}

\begin{abstract}
With the progress of metallurgical activities, more and more dumped slag heaps emerge as valuable deposits to feed the growing need for metal resources. Detecting, quantifying, and reextracting metals from these slags may complement the prospection of new ore deposits. However, the spatial delineation of the slag heap cannot easily be obtained from the resistivity distribution alone (determined either with galvanometric or with induction-based methods). Although the magnetic method can detect slag heaps, it fails to make an estimation of the quantity of metal present in the slag. Alternatively, the induced polarization (IP) method can be
\end{abstract}

used to fulfill this goal. The complex conductivity responses of slag samples from a slag heap in France are obtained in the laboratory. These data are used to assess the grade of the slag, which is close to $8 \%$. Then, a least-squares 3D IP inversion is used to get the subsurface chargeability distribution delimiting the slag heap in the ground. From the linear relationship determined between the chargeability and the volumetric metal content or the volumetric slag content, the metallic volume of the slag heaps can be directly determined. This approach is used at the site of Saint-Vincent sur L'Isle, Dordogne (France), where it allows characterizing the shape of a slag heap and quantifying the total cumulative metal content of the investigated area.

\section{INTRODUCTION}

Metal resources helped build modern societies, and today they remain an integral component of our development. With global industrialization and population increases, there is a surging need for metals to fulfill the growing demand. Except prospecting and exploiting of new mineral deposits, which is commonly seen as the main method to partially meet the demand, there are also some other complementary methods, such as scrap metal recycling (Damgaard and Christensen, 2011). During the history of metallurgical activities, slag have been piled, dumped, and buried (Beck et al., 2008). With the technological progress in metallurgy, previously dumped slag heaps can become valuable deposits worth being reinvestigated (Günther and Martin, 2016). Geophysical investigation of slag deposits is usually done because of the contamination problems they may represent (Banks et al., 1997). Investigating ancient metallurgical slag heaps from smithing may also have archeological implications regarding the past production of iron in these areas (Decombeix et al., 1998). Finally, the type of investigation discussed below may have application to the monitoring of bioleaching (Ogbonna et al., 2006).

In this paper, we are interested exclusively in the detection and quantification of metallurgical slags from iron silicate smithing. Such slag deposits cannot be easily detected using the electrical resistivity distribution determined by the means of galvanometric or electromagnetic (EM) methods. Although the magnetic method can localize slag heaps due to the magnetic properties of the metallic particles (essentially associated with the presence of magnetite), it cannot quantify the metallic content of the slag because the magnetic field lines do not conserve the magnetic flux (Florsch et al., 2011, 2012). Among the arsenal of geophysical methods that we

Manuscript received by the Editor 18 November 2017; revised manuscript received 18 March 2018; published ahead of production 07 June 2018 ; published online 19 July 2018

${ }^{1}$ Université Grenoble Alpes, CNRS, IRD, IFSTTAR, ISTerre, 38000 Grenoble, France and Université Savoie Mont Blanc, ISTerre, 73000 Chambéry, France. E-mail: uzhengqi@gmail.com; abdellahi.soueid-ahmed@univ-smb.fr; andre.revil@univ-smb.fr.

${ }^{2}$ Yazd University, Department of Mining and Metallurgical Engineering, Yazd, Iran. E-mail: aghorbani@yazd.ac.ir.

Sorbonne Université, UPMC Univ Paris 06, CNRS, EPHE, UMR 7619 Metis, 75005 Paris, France. E-mail: feras.abdulsamad@upmc.fr; nicolas.florsch@ upme.fr.

${ }^{4}$ UBM CNRS UMR 5607 Ausonius, Bordeaux, France. E-mail: jeremy-bonnenfant@orange.fr.

(C) 2018 Society of Exploration Geophysicists. All rights reserved. 
have, the induced polarization (IP) method is probably the most meaningful to fulfill our goals (Florsch et al., 2011, 2012, 2017).

IP is a nonintrusive method that works on the basis of the capacitive characteristics of porous media. In other words, it can map a property called chargeability, reflecting the ability of a material to reversibly store electrical charges under the action of a primary electrical field or electrical current. The iron slag can be considered itself as a porous medium with dispersed metallic grains and notable polarization responses have been reported for such materials (Ul1rich et al., 2008; Florsch et al., 2011, 2012; Günther and Martin, 2016). This phenomenon makes IP a suitable and appealing method to detect buried slag heaps.

The underlying physical theory of dispersed metallic particles in a porous matrix can be found in the previous papers of this series (Revil et al., 2015a, 2015b). In the first paper in this series (Revil et al., 2015a), using a physics-based model, we proposed a set of simple relationships to model the complex conductivity of dispersed ores based on the effective medium theory. This model was validated in the subsequent papers (Revil et al., 2015b, 2017b, 2017c). More precisely, a simple linear relationship between the chargeability and the volume fraction of metallic particles of the porous media was developed based on theoretical arguments and tested on semiconductors, metals, and semimetals. This relationship will be further tested and used in this paper in the context of slag heaps. This relationship makes the quantification of the metallic content in the slag heaps a reality provided that the chargeability distribution of the ground is reliably inverted.

Although the IP method has been widely used in many disciplines of earth sciences, applications of this method to slag heaps are still relatively scarce. The quantitative determination of the metal content is a task that has never been completed so far. Weller et al. (2000), Ullrich et al. (2008), and Meyer et al. (2007) use the IP method on slag heaps. Ullrich et al. (2007) describe an empirical procedure to evaluate the volume of the slag heaps in Munigua (Spain). The contours of

\section{Representative elementary volume}
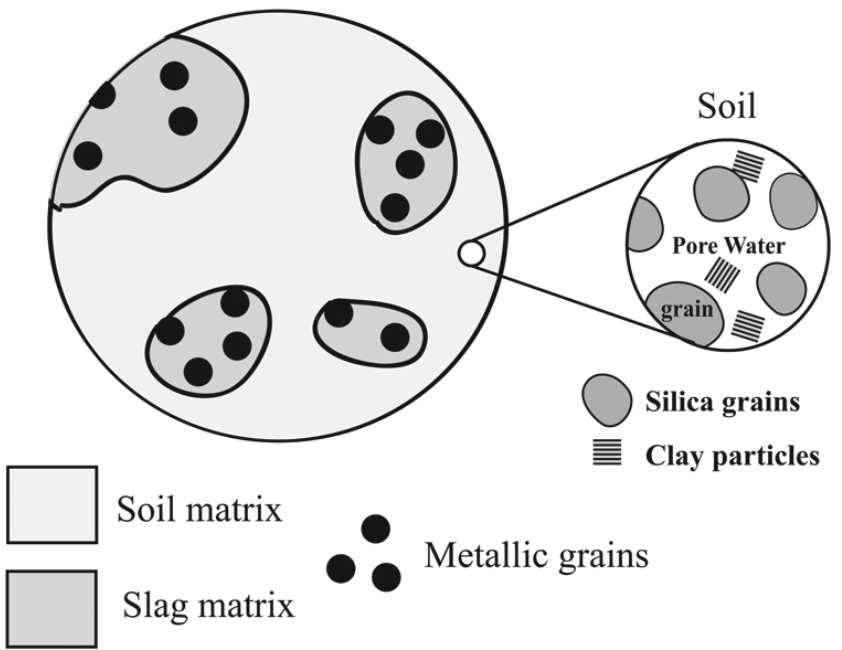

Soil matrix

Slag matrix

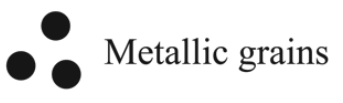

Figure 1. Representative elementary volume of a mixture of slag and soil. The background material around the metallic particles is formed by the combination of the slag and soil matrices, which are porous and are characterized by a low polarizability by comparison with the polarization characteristics of the metallic grains (semiconductors, semimetals, and metals). the slag heap were identified based on a phase isovalue of $30 \mathrm{mrad}$. Considering the total volume of the slag heaps $\left(2800-3000 \mathrm{~m}^{3}\right)$, the average density of the slag, and the empirical ratio between the slag and the metal (10:1), a total production of approximately 1000 tons of metal was determined by the approach used. Their approach is however empirical, whereas we propose a more mechanistic approach supported by a high number of experimental data sets, as reported in our previous papers. Florsch et al. $(2011,2012)$ show the potential of the IP method for the detection and the quantification of the slag heaps; they quantify the slag content rather than the metallic content of the slag. That said, the metallic contents are far more meaningful than the slag content in terms of determining the total quantity of metal still present in the slag heap.

This paper can therefore be seen as an application of the previous papers in this series (Revil et al., 2015a, 2015b, 2017b, 2017c; Mao and Revil, 2016; Mao et al., 2016). We are interested in combining petrophysics and field measurements to demonstrate that the metal content of a slag heap can be determined quantitatively. The paper is organized as follows. We first summarize the main findings of our previous papers, and we apply them to slag heaps. Laboratory experiments are then conducted on slag samples to check the relationship between the chargeability and the metal content. 3D IP inversion is used to obtain the chargeability distribution in the ground at a field test site in France to determine the metal content at this site.

\section{UNDERLYING THEORY}

\section{Cole-Cole representation of the complex conductivity}

First, we summarize the findings obtained in the previous papers of this series (Revil et al., 2015a, 2015b, 2017b, 2017c; Mao and Revil, 2016; Mao et al., 2016). We consider the type of mixture sketched in Figure 1 and described physically in Appendices A and $\mathrm{B}$. To account for electromigration and diffusion of the charge carriers in their concentration fields, Ohm's law can be written as (Olhoeft, 1985)

$$
\mathbf{J}=\sigma^{*} \mathbf{E}=\left(\sigma^{\prime}+i \sigma^{\prime \prime}\right) \mathbf{E},
$$

where $\mathbf{J}$ (in $\mathrm{A} \mathrm{m}^{-2}$ ) denotes the total current density, $\mathbf{E}$ denotes the electrical field $\left(\mathrm{V} \mathrm{m}^{-1}\right), i=\sqrt{-1}$ is the pure imaginary number, and $\sigma^{*}$ (in $\mathrm{S} \mathrm{m}^{-1}$ ) denotes the complex conductivity. The real part $\sigma^{\prime}$ (in-phase component) of the complex conductivity $\sigma^{*}$ is related to the electromigration processes affecting the charge carriers, whereas the imaginary part $\sigma^{\prime \prime}$ (quadrature component) denotes their ability to be stored in the material (capacitive effect). The phase $\varphi$ (in $\mathrm{rad}$ ) is defined as $\tan \varphi=\sigma^{\prime \prime} / \sigma^{\prime}$.

Buried metals are not easily observed by resistivity tomography alone (Florsch et al., 2011, 2012) because metallic targets can behave as insulators at low frequency (see Mao et al., 2016). However, dispersed metallic bodies have a strong ability to polarize in an electrical field (Marshall and Madden, 1959; Wynn et al., 1985; Ostrander and Zonge, 1978; Misra et al., 2016a, 2016b). To quantify slag heaps, an appropriate mathematical model must be introduced based on the representative elementary volume shown in Figure 1.

The Cole and Cole (1941) model is known to prevail over other models by providing a simple yet accurate representation of IP spectra of disseminated ore (Zonge and Wynn, 1975; Pelton et al., 1978; Yuval and Oldenburg, 1997). With this parametric representation, the complex conductivity entering equation 1 is written as 


$$
\sigma *(\omega)=\sigma_{\infty}\left[1-\frac{M}{1+\left(i \omega \tau_{0}\right)^{c}}\right],
$$

where $\omega$ denotes the angular frequency, $0 \leq c \leq 1$ denotes the Cole-Cole exponent (dimensionless), $\tau_{0}$ denotes the time constant (in s), $M=\left(\sigma_{\infty}-\sigma_{0}\right) / \sigma_{\infty}$ denotes the intrinsic total chargeability (dimensionless but sometimes expressed in $\mathrm{mVV}^{-1}$ ) with $0 \leq M \leq 1$, and $\sigma_{0}\left(<\sigma_{\infty}\right)$ and $\sigma_{\infty}$ (both in $\mathrm{S} / \mathrm{m}$ ) denote the DC $\left(\omega \tau_{0} \ll 1\right)$ and high-frequency or "instantaneous" $\left(\omega \tau_{0} \gg 1\right)$ electrical conductivities, respectively (see Figure 2). The Cole-Cole model given by equation 2 corresponds to the low-frequency component of the double Cole-Cole model described in Appendix C. With the introduced Cole-Cole model, relationships can be found between the Cole-Cole parameters and the medium properties. As our previous theoretical analyses and laboratory results revealed, the intrinsic total chargeability is the best parameter to characterize metallic bodies in the porous medium because there is a simple linear relationship between the total chargeability and the metallic volumetric content (see Figure 3 ). This is true as far as the volume fraction of metal is $<33 \%$, which is normally satisfied for the slag heaps. The chargeability $M$ of the mixture of the background material and the metallic particles is related to the volume fraction of metallic particles $\varphi_{m}$ as (Revil et al., 2015a, 2015b, 2017b, 2017c; see the discussion in Appendices A and B, and see Figure 3)

$$
\begin{gathered}
M=1-\left(1-M_{b}\right)\left(1-M_{m}\right), \\
M=\frac{9}{2} \varphi_{m}+M_{b},
\end{gathered}
$$

where $M_{m}=(9 / 2) \varphi_{m}$ denotes the chargeability associated with the metallic particles themselves and $M_{b} \ll 1$ denotes the chargeability of the background material alone. The chargeability of the background material is roughly a constant (at a given salinity) when plotted as a function of the cation exchange capacity (CEC) of the material (Figure 4). This CEC is used as a proxy of the specific surface area of the material and, at a given mineralogy, of the clay content. A model of the chargeability of the background is discussed in Appendix A. At low salinity, we have $M_{b}=R=$ $8 \times 10^{-2}$ independent on saturation, temperature, and salinity (in the low-salinity regime).

The chargeability of the material is related to the grade of slag $G$ (mass fraction of metal in the slag) by a relationship derived in Appendix B:

$$
M=\frac{9}{2}\left(\frac{G \rho_{\text {slag }}}{\rho_{m}}\right) \varphi_{\text {slag }}+M_{b},
$$

where $\varphi_{\text {slag }}$ denotes the volume fraction of slag in the representative elementary volume shown in Figure $1, \rho_{\text {slag }}$ and $\rho_{m}$ denote the mass density

a) of the slag and metallic particles, respectively. In the laboratory experiment described below, the background material will be the sand and the nonmetallic material around the metallic particles in the slag. This means that with the subsurface distribution of the total chargeabilities, we can directly estimate the metallic content from IP data.

\section{Time-domain versus frequency-domain IP}

Based on the difference between the transmitter waveforms, the IP method can be operated either in the time domain (TDIP) or in the frequency domain, the latter method is often called spectral IP (SIP) when multiple frequencies are used. SIP prevails over TDIP by its wider frequency range and the resulting richer information. TDIP is usually used in the field because most resistivity meters can

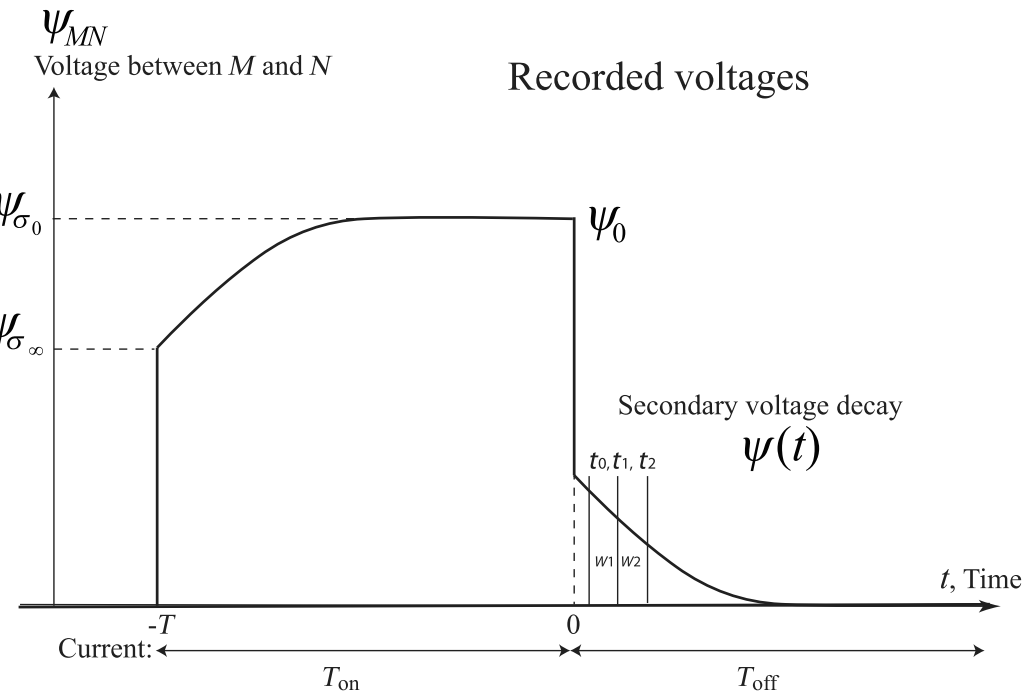

b) Instantaneous and direct current conductivities

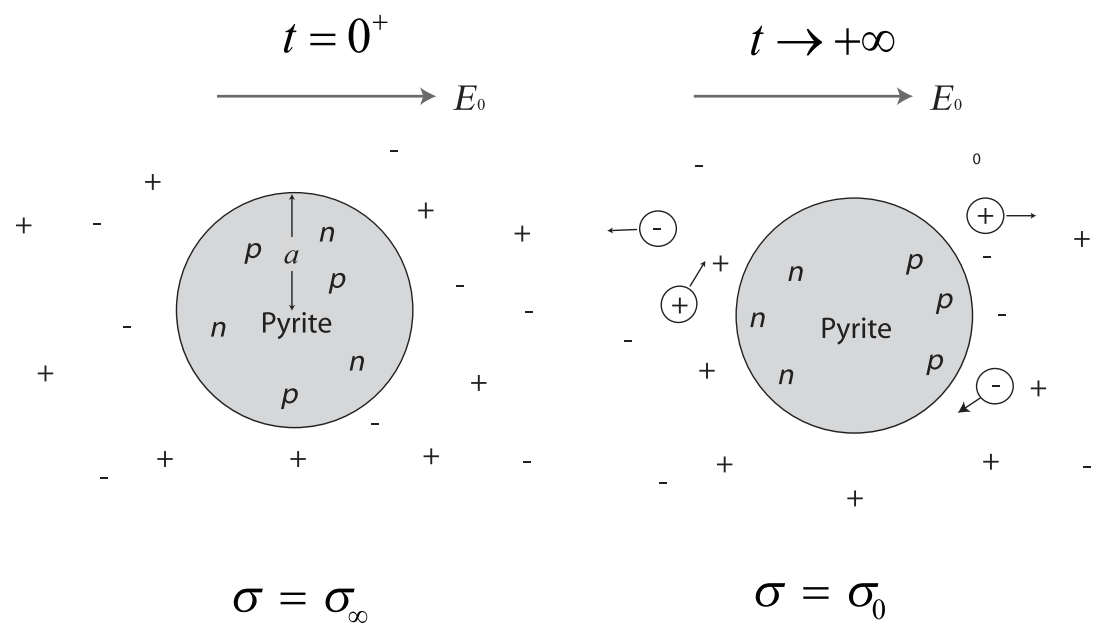

Figure 2. Polarization of metallic particles. (a) Measured potential difference between two voltage electrodes $\mathrm{M}$ and $\mathrm{N}$ for an alternating box current input (through current electrodes $\mathrm{A}$ and $\mathrm{B})$. The decaying secondary voltage is decomposed into windows $\left(W_{1}\right.$, $W_{2}$, etc.) separated by characteristic times $\left(t_{0}, t_{1}, t_{2}\right.$, etc.). (b) The difference between the instantaneous conductivity and the DC conductivity is due to the polarization of the metallic grains of a diameter $a$. The $n$ and $p$ charge carriers correspond to the electrons and p-holes in the metallic particles, which are both mobile. The characteristic time for the relaxation of the charge carriers is related to the size of the metallic grains and the conductivity of the background. 
operate TDIP measurements. In TDIP, a bipolar periodic square current waveform is used. The secondary voltage curve is measured after the shutdown of the primary current (Figure 2a). Using these

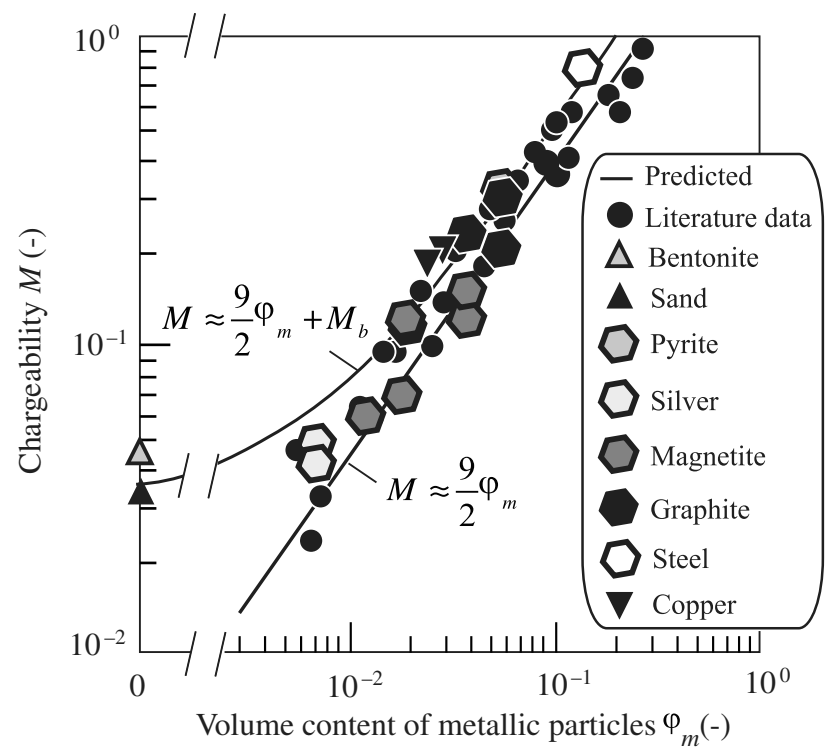

Figure 3. Chargeability of metallic particles $M$ versus the volumetric content of metallic particles in a material $\varphi_{m}$. The metallic particles include semiconductors, semimetals, and metals (literature data correspond to pyrite). At a low concentration of metallic particles, the chargeability is dominated by the chargeability of the background $M_{b}$ (modified from Revil et al., 2017b, 2017c). The chargeability of the background $M_{b}$ is typically less than 0.05 .

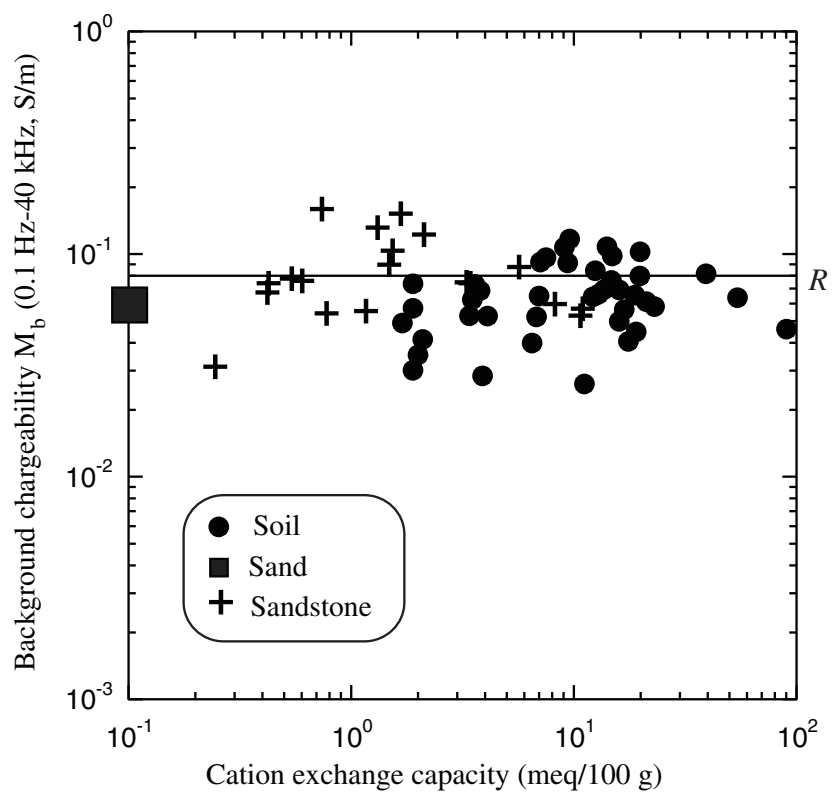

Figure 4. Low-salinity chargeability of the background material $M_{b}$ versus the CEC of the material, which is generally a proxy for the quantity of clay minerals present in the material. The chargeability of the background material usually decreases with the conductivity of the pore water (modified from Revil et al., 2017a; the sandstone data are from Vinegar and Waxman, 1984). It is typically around 0.08 $(80 \mathrm{mV} / \mathrm{V})$ at low salinities, as discussed in Appendix A. A threshold at $M_{b}=0.08$ allows us to remove the background chargeability. voltage values, one can derive the partial apparent chargeability in each window. During the secondary voltage decay $\psi(t)$, considering two times $t_{1}$ and $t_{2}>0(t=0$ corresponds to the shutdown of the primary current), the partial chargeability is defined as

$$
M_{t_{1}, t_{2}}=\frac{1}{\psi_{0}} \int_{t_{1}}^{t_{2}} \psi(t) d t,
$$

where $\psi_{0}$ denotes the difference of potential between the electrodes $M$ and $N$ just before the shutdown of the primary current and $\psi(t)$ denotes the secondary voltage decaying curve between electrodes $M$ and $N$ (Figure 2). The partial chargeability and the chargeability are related to each other by

$$
M_{t_{1}, t_{2}}=M\left(t_{2}-t_{1}\right)
$$

as long as the two times $t_{1}$ and $t_{2}$ are chosen, such as $t_{1}<t_{2} \ll \tau$ (Florsch et al., 2011). Because the inverted partial chargeability in the first window is the total chargeability times a time constant $\Delta t=t_{2}-t_{1}$, as shown in equation 7 , it must also obey a linear relationship with the metallic particle content.

\section{LABORATORY EXPERIMENTS}

Our goal here is to look at a relationship between the slag content and the chargeability in the laboratory and to demonstrate that these measurements can be used to assess the grade of the slag. A sketch of the experimental setup is shown in Figure 5a. The potential electrodes are nonpolarizable $\mathrm{Cu} / \mathrm{CuSO}_{4}$ electrodes with a diameter of $6 \mathrm{~mm}$ (for details, see Florsch et al., 2011). The current electrodes are tinfoil located on both end faces of the sandbox, which is filled with the sand and slag. These current electrodes are used to inject a uniform current through the sandbox. The complex conductivity experiments reported in this section were made with the ZEL-SIP04V02 impedance meter (see Figure 5b and Zimmermann et al., 2008). The spectra were obtained in the frequency range of $1 \mathrm{~Hz}$ to $45 \mathrm{kHz}$.

The slag samples used in this section are iron-rich slags (see the composition in Table 1 for seven cores) from the test site discussed below in this paper. There are dark-gray relatively dense and porous materials. The bulk density of the water-saturated slag is approximately $2600 \pm 100 \mathrm{~kg} \mathrm{~m}^{-3}$ (see Table 2). The grain density is approximately $3480 \pm 100 \mathrm{~kg} \mathrm{~m}^{-3}$, and the porosity is $0.32 \pm 0.05$. The sand is a pure silica sand, with a mean grain diameter of $160 \mu \mathrm{m}$ and a porosity of $40 \%$.

We used the following procedure to measure the mass and volumetric content of slag in mixed sand and slag tank. Sand was first saturated with a $\mathrm{NaCl}$ electrolyte at a conductivity of $0.05 \mathrm{~S} \mathrm{~m}^{-1}$ (at $25^{\circ} \mathrm{C}$ ). We first filled the tank with this sand. The mass and volume of saturated sand used in the sandbox were precisely measured. We subsequently added pieces of slag (saturated at a pore-water conductivity of $0.05 \mathrm{~S} \mathrm{~m}^{-1}, \mathrm{NaCl}, 25^{\circ} \mathrm{C}$ ) in the sandbox, step by step, and we removed exactly the same volume of saturated sand from the sandbox. Each time that we added a piece of slag, a conductivity spectrum was performed. The final mass fraction of slag in the sandbox was 0.27 . The saturation of the slag with the brine was done in vacuum conditions, $48 \mathrm{~h}$ before performing the sandbox experiment. This allows the slag to be completely saturated.

Figure $6 a-6 c$ shows the in-phase conductivity, quadrature conductivity, and phase spectra for different slag contents. The in-phase conductivity decreases with the increase of the slag content. This 
suggests that the conductivity of slag particles is smaller than the conductivity of saturated sand. The conductivity of the brine-saturated slag core was measured, and we obtained $0.008 \mathrm{~S} \mathrm{~m}^{-1}$ at $1 \mathrm{~Hz}$ (we used $\mathrm{Ag} / \mathrm{AgCl}$ medical electrodes as potential electrodes and self-adhesive carbon film electrodes as current electrodes; see Cosenza et al., 2007). The in-phase conductivity of the saturated sand is $0.027 \mathrm{~S} \mathrm{~m}^{-1}$ at $1 \mathrm{~Hz}$, so it is larger than the conductivity of the slag (Figure 6a).

The quadrature conductivity of the mixture of sand and slag increases when slag content increases (Figure $6 \mathrm{~b}$ and $6 \mathrm{c}$ ). This is due to the IP effect of metallic grains in the slag (Revil et al., 2017b). We inverted the impedance amplitude and phase spectra of laboratory measurements using a double Cole-Cole parametric model (Pelton et al., 1978; see Appendix C for details). The inversion code was written in MATLAB and is based on Bayesian inference (Ghorbani et al., 2007). It searches the maximum of probability function using a Markov chain Monte Carlo (MCMC) sampler (Chen et al., 2008). Table 3 provides inverted Cole-Cole parameters, and Figure $6 \mathrm{~d}$ shows the low-frequency Cole-Cole chargeability versus the volumetric content of slag.

Equation 5 can be written as $M=a \varphi_{\text {slag }}+b$. From Figure 6d, we have $a=\left(9 G \rho_{\text {slag }} / 2 \rho_{m}\right)=$ 0.126 and $b=M_{b}=0.003$ (background chargeability). From the model discussed in Appendix A, it is not surprising to find such a low background chargeability $\left(M_{b} \ll R=8 \times 10^{-2}\right)$ for the sand because it is characterized by a very low surface conductivity. Taking $\rho_{m}=7800 \mathrm{~kg} \mathrm{~m}^{-3}$, $\rho_{\text {slag }}=2600 \pm 100 \mathrm{~kg} \mathrm{~m}^{-3}$ (see Table 2), the grade of the slag is $G=0.084$; i.e., the mass fraction of metal in the slag is $8.4 \%$ on average, which is reported in Table 2.

The frequency effect (FE; dimensionless) is defined by $\mathrm{FE}=\left(\rho_{0}-\rho_{\infty}\right) / \rho_{\infty}$ (and $M=\mathrm{FE} /$ $(\mathrm{FE}+1)$ ), where $\rho_{0}=1 / \sigma_{0}$ and $\rho_{\infty}=1 / \sigma_{\infty}$ denote the DC resistivity and the high-frequency instantaneous resistivity, respectively. In our case, we use $\mathrm{FE}=(\rho(1 \mathrm{~Hz})-\rho(1 \mathrm{kHz})) / \rho(1 \mathrm{kHz})$. Figure 7 shows the phase (determined at $10 \mathrm{~Hz}$ ) and the $\mathrm{FE}$ as a function of the volumetric content of slag. We see that these two parameters can also be related to the volumetric content of slag (or to the mass content of slag), but the relationship between these two IP parameters and $\varphi_{\text {slag }}$ is nonlinear.

\section{INDUCED-POLARIZATION TOMOGRAPHY}

\section{Algorithm}

As widely described in the literature, the classic approach to invert time-domain IP data is to
Table 1. Composition of seven slag samples in weight $\%$ from the investigated heap (using the ICP-AES technique, measurements done by 'Service d'Analyses des Roches et des Minéraux du Centre de Recherches Pétrographiques et Géochimiques" from Nancy, France).

\begin{tabular}{lccccccccc} 
Samples & $\mathrm{Al}_{2} \mathrm{O}_{3}$ & $\mathrm{Fe}_{2} \mathrm{O}_{3}$ & $\mathrm{MnO}$ & $\mathrm{MgO}$ & $\mathrm{CaO}$ & $\mathrm{Na}_{2} \mathrm{O}$ & $\mathrm{K}_{2} \mathrm{O}$ & $\mathrm{TiO}_{2}$ & $\mathrm{P}_{2} \mathrm{O}_{5}$ \\
\hline LGBSCOR001 & 5.16 & 61.67 & 0.61 & 0.44 & 1.54 & 0.05 & 1.16 & 0.29 & 0.14 \\
LGBSCOR002 & 6.71 & 63.20 & 0.43 & 0.42 & 1.93 & 0.05 & 1.19 & 0.32 & 0.21 \\
LGBSCOR003 & 4.77 & 64.27 & 0.44 & 0.41 & 1.97 & 0.03 & 0.90 & 0.24 & 0.27 \\
LGBSCOR004 & 4.35 & 67.09 & 0.53 & 0.42 & 1.80 & 0.04 & 1.12 & 0.24 & 0.25 \\
LGBSCOR005 & 4.82 & 61.26 & 0.60 & 0.40 & 2.33 & 0.03 & 1.31 & 0.27 & 0.25 \\
LGBSCOR006 & 4.17 & 74.71 & 0.39 & 0.25 & 1.29 & 0.02 & 0.68 & 0.21 & 0.29 \\
LGBSCOR007 & 3.77 & 70.91 & 0.54 & 0.44 & 2.38 & 0.03 & 1.03 & 0.20 & 0.40
\end{tabular}

Table 2. Properties of the sand and slag used in the sandbox experiments. The slag samples have been extracted from the test site corresponding to the field study discussed in the main text. The porosity and grain density were determined by measuring the value of the core sample and its dry and watersaturated weights. The grade was determined from the approach discussed in the main text.
Property

Symbol

Porosity of the sand

Porosity of the slag

Mass density of the sand

Mass density of the water-saturated slag

Grain density of the slag

Grain density of the metallic grains

Grade

$\begin{array}{cc}\phi_{\text {sd }} & 0.40 \pm 0.03 \\ \phi_{\text {slag }} & 0.32 \pm 0.05 \\ \rho_{\text {sd }} & 2000 \mathrm{~kg} \mathrm{~m}^{-3} \\ \rho_{\text {slag }} & 2600 \pm 100 \mathrm{~kg} \mathrm{~m}^{-3} \\ \rho_{\text {slag }}^{g} & 3480 \pm 100 \mathrm{~kg} \mathrm{~m}^{-3} \\ \rho_{m} & 7800 \mathrm{~kg} \mathrm{~m}^{-3} \\ G & 0.084\end{array}$

a)

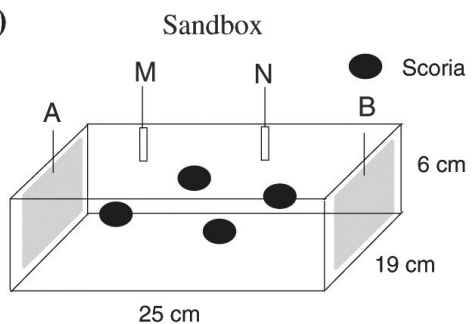

A, B Current electrodes; M, N Potential electrodes

c)

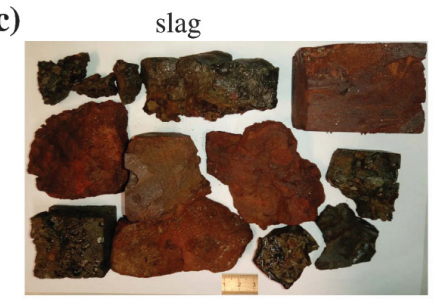

b) Amplifier unit ZEL-SIP04-V02

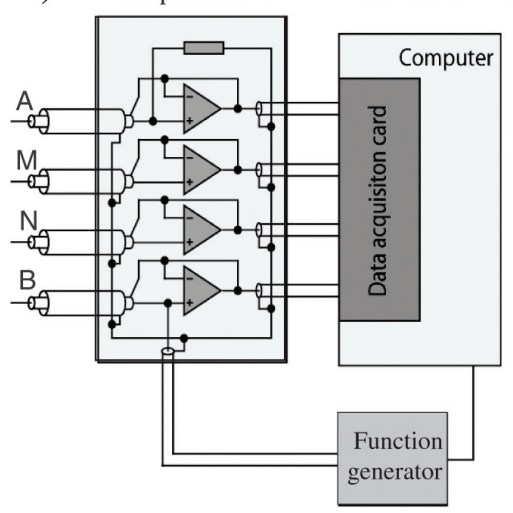

Figure 5. Laboratory experiment. (a) Sketch of the sandbox, where A and B denote the current electrodes (tinfoil) and $\mathrm{M}$ and $\mathrm{N}$ denote the voltage electrodes $\left(\mathrm{Cu} / \mathrm{CuSO}_{4}\right.$ nonpolarizing electrodes). (b) ZEL-SIP04-V02 impedance meter (designed by Zimmermann et al., 2007, 2008) used to perform SIP spectra. (c) Pieces of slag used in the sandbox experiment (the scale corresponds to $3 \mathrm{~cm}$ ). 
apply the method proposed by Seigel (1959). In this approach, the polarization effect is treated as a perturbation of the ground conductivity. More precisely, the DC conductivity $\sigma_{0}$ is related to the instantaneous conductivity $\sigma_{\infty}$ by (Seigel, 1959; see also Figure 2b)

$$
\sigma_{0}=(1-M) \sigma_{\infty}
$$

The inversion of the secondary voltage decaying function can then be treated with a two-step procedure (Oldenburg and $\mathrm{Li}, 1994)$. In the first step, the inversion of the instantaneous conductivity $\sigma_{\infty}$ is performed without a polarization effect. In the second step, an inversion of the
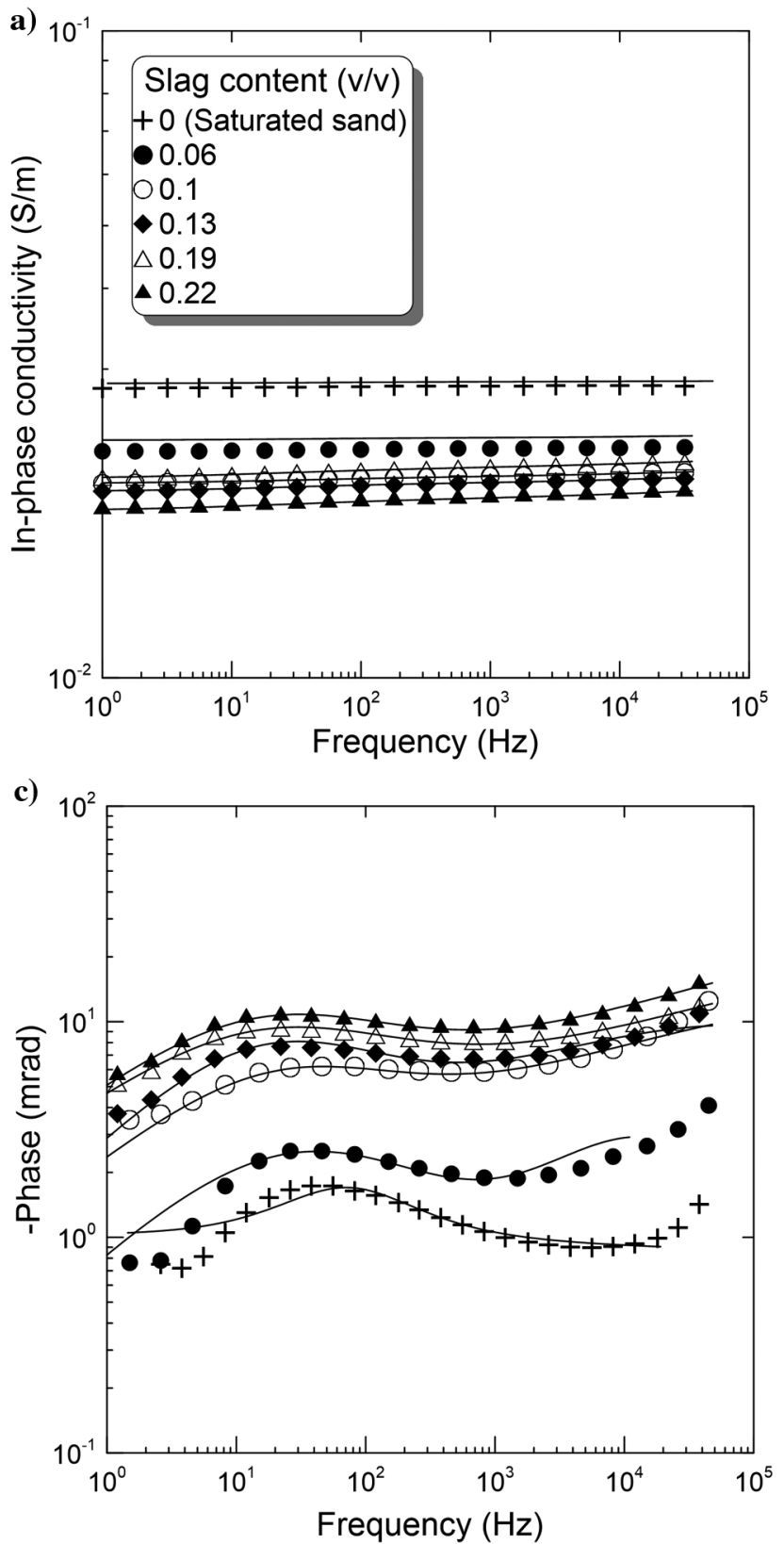

chargeability is carried out using the conductivity distribution obtained in the first step.

Because the frequency of the bipolar periodic transmitter waveform is low enough, the quasistatic approximation of Maxwell's equations can be used by neglecting the magnetic induction and the displacement current. The scalar potential $\psi_{\sigma_{\infty}}$ (in V) is introduced to ease the calculation of the Maxwell's equations in this situation. The governing equations are formed by the Poisson's equation as

$$
\nabla \cdot\left(\sigma_{\infty} \nabla \psi_{\sigma_{\infty}}\right)=-I \delta\left(\mathbf{r}-\mathbf{r}_{s}\right)
$$
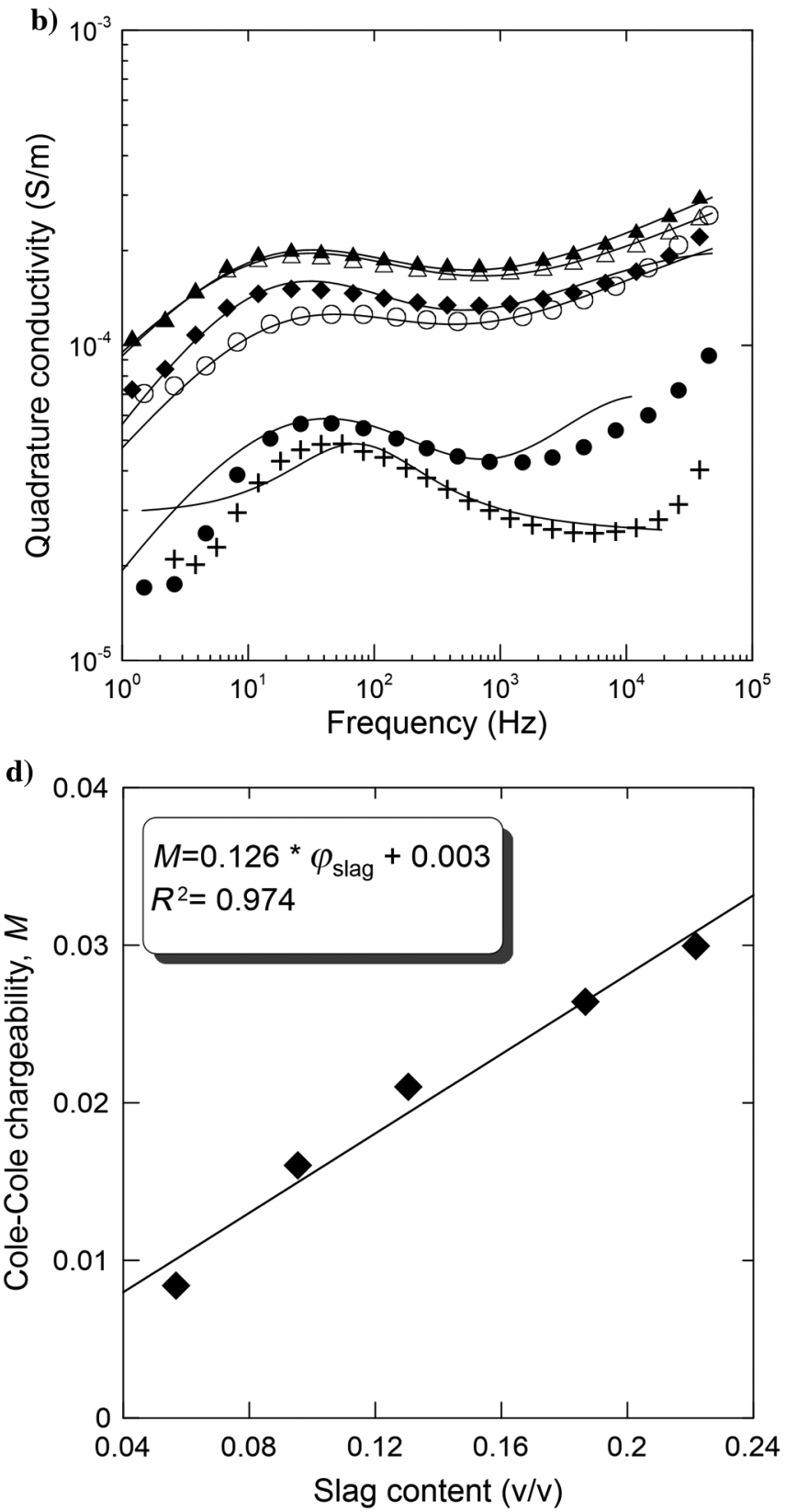

Figure 6. The SIP measurements in the laboratory on saturated sand and the slag particle mixture. (a) In-phase conductivity, (b) quadrature conductivity, and (c) phase. In these three plots, the solid lines correspond to the fit of the data with a double Cole-Cole model. The optimized values of the Cole-Cole parameters are reported in Table 3 (see the modeling in Appendix C). In the absence of slag (i.e., for a volume fraction of $\varphi_{\text {slag }}=0$ ), the sandbox is fully filled with the saturated sand. (d) Chargeability versus volume fraction of slag. 
with the following boundary conditions at the earth's surface:

$$
\frac{\partial \psi_{\sigma_{\infty}}}{\partial n}=0,
$$

where $\sigma_{\infty}$ denotes the earth's instantaneous conductivity; $n$ denotes the unit normal vector to ground surface; $I$ is the injected current (in A); and $\delta\left(\mathbf{r}-\mathbf{r}_{s}\right)\left(\mathrm{m}^{-3}\right)$ denotes the delta function, where $\mathbf{r}$ and $\mathbf{r}_{s}$ are the vector position and the position vector of the current source, respectively. The potential is taken equal to zero at the other boundaries placed far away from the domain of interest to mimic infinity.

The objective function $\mathbf{P}(\mathbf{m})$ we want to minimize is given by

$$
\mathbf{P}(\mathbf{m})=\left\|\mathbf{W}_{d}\left(\mathbf{d}(\mathbf{m})-\mathbf{d}_{\mathrm{obs}}\right)\right\|^{2}+\lambda\left\|\mathbf{W}_{m} \mathbf{m}\right\|^{2},
$$

where $\mathbf{m}$ is the $n$-model vector corresponding to the logarithm of the conductivity of each cell, $\mathbf{d}(\mathbf{m})$ and $\mathbf{d}_{\mathrm{obs}}$ are the forward and measured apparent resistivity data $m$-vectors, respectively, and $\lambda$ is the regularization parameter that balances the data misfit (first term of the right side of equation 11) and the regularizer (last term of equation 11). Usually, we have $m \ll n$ and the problem is underdetermined. The matrix $m \times m \mathbf{W}_{d}$ is the data covariance matrix that is generated from the measured standard deviations on the measurements, and matrix $n \times n \mathbf{W}_{m}$ is considered to be the first-order gradient matrix. Minimizing the objective function with respect to the model vector, we obtain the following iterative solution for the model vector:

$$
\mathbf{m}_{k+1}=\mathbf{m}_{k}+\delta \mathbf{m},
$$

where the perturbation of the model vector is

$$
\begin{aligned}
\delta \mathbf{m}= & -\left[\mathbf{J}^{T}\left(\mathbf{W}_{d}^{T} \mathbf{W}_{d}\right) \mathbf{J}+\lambda \mathbf{W}_{m}^{T} \mathbf{W}_{m}\right]^{-1} \\
& \times\left[\mathbf{J}^{T}\left(\mathbf{W}_{d}^{T} \mathbf{W}_{d}\right)\left(\mathbf{d}\left(\mathbf{m}_{i}\right)-\mathbf{d}_{\mathrm{obs}}\right)+\lambda \mathbf{W}_{m}^{T} \mathbf{W}_{m} \mathbf{m}_{k}\right],
\end{aligned}
$$

and where $\mathbf{A}^{\mathrm{T}}$ denotes the transpose of matrix $\mathbf{A}$ (A being a general matrix). Calculating sensitivity matrix $\mathbf{J}$ is the most time-intensive part in the optimization. We use the reciprocity method to calculate the first sensitivity matrix and then update the sensitivity matrix using Broyden's method at each iteration (Loke and Barker, 1996). Convergence is reached when the perturbation model vector is smaller than a threshold. We use the reciprocity method to calculate the first sensitivity matrix, and then

Equation 13 can be used to rerun the forward modeling, and "the chargeability potential" $\Psi_{\sigma_{0}}$ will be obtained. The apparent chargeability $M_{a}$ is defined as

$$
M_{a}=\frac{\Psi_{\sigma_{\infty}}-\Psi_{\sigma_{0}}}{\Psi_{\sigma_{\infty}}}
$$

During the inversion, $M_{a}$ appearing in equation 14 is treated as the measured chargeability. The chargeability sensitivity matrix can be scaled from the conductivity sensitivity matrix that we have already computed during the conductivity inversion. After some mathematical derivation, the relationship is

$$
\frac{\partial d_{i}}{\partial \log M_{j}}=-\frac{M_{j}}{1-M_{j}} \frac{\Psi_{\sigma \mid i}}{\left(\Psi_{M \mid i}\right)^{2}} \frac{\partial \Psi_{M \mid i}}{\partial \log \sigma_{j}^{*}}
$$

After building a new forward function for the chargeability parameter and also some relevant changes, we can modify the program that we invert the conductivity above to invert the chargeability here.

\section{Benchmark test}

First, we benchmark our inverse code on a synthetic test case that is representative of real-field conditions. We used the geostatistical software SGEMS (Deutsch and Journel, 1992) to generate the true conductivity and chargeability fields based on an isotropic semivariogram (the properties are reported in Table 4). We generated moderately heterogeneous continuous fields that indeed are realistic and quite illustrative of the real conductivity and chargeability distribu-

Table 3. Inverted parameters of the double Cole-Cole model used to fit the complex conductivity spectra laboratory. The inversion is done with e-Cole model is used to represent the low-frequency dispersion associated

\begin{tabular}{ccccccccc}
$\varphi_{\text {slag }}$ & $\sigma_{0}$ & $M_{1}$ & $M_{2}$ & $c_{1}(-)$ & $c_{2}(-)$ & $\tau_{1}(\mathrm{~s})$ & $\tau_{2}(\mathrm{~s})$ & $\mathrm{rms}(\%)$ \\
\hline 0.22 & 0.018 & 0.030 & 0.334 & 0.59 & 0.22 & 0.0085 & $1.07 \times 10^{-09}$ & 0.151 \\
0.19 & 0.020 & 0.026 & 0.404 & 0.57 & 0.20 & 0.0086 & $5.99 \times 10^{-11}$ & 0.134 \\
0.139 & 0.019 & 0.021 & 0.063 & 0.65 & 0.36 & 0.0076 & $2.13 \times 10^{-06}$ & 0.262 \\
0.096 & 0.020 & 0.016 & 0.108 & 0.61 & 0.28 & 0.0063 & $9.11 \times 10^{-08}$ & 0.140 \\
0.057 & 0.023 & 0.008 & 0.010 & 0.72 & 0.58 & $1.07 \mathrm{E}-05$ & 0.0045 & 0.805 \\
\hline
\end{tabular}


Table 4. Relevant information about the synthetic and field case studies. ERT and IP are the abbreviations of electrical resistance tomography and induced polarization methods, respectively; $\boldsymbol{n}$ and $\boldsymbol{m}$ denote the number of model parameters and the number of data, respectively; $\boldsymbol{k}$ denotes the number of iteration at which the inversion reached the convergence; $h$ and $j$ denote the number of profiles and the number of electrodes per profile; and $R^{2}$ is the coefficient of determination.

\begin{tabular}{lcc} 
Property & Synthetic case study & Field case study \\
\hline Dimension & $3 \mathrm{D}$ & $3 \mathrm{D}$ \\
Core domain & $18 \times 14 \times 6 \mathrm{~m}$ & $28 \times 24 \times 10 \mathrm{~m}$ \\
$n$ & 6154 & 41,876 \\
$m$ & 372 (ERT), 372 (IP) & 3150 (ERT) 3150 (IP) \\
$k$ & 6 (ERT), 6 (IP) & 6 (ERT), 9 (IP) \\
$h$ & 6 & 21 \\
$j$ & 15 & 24 \\
$R^{2}(\mathrm{ERT})$ & 0.83 & 0.90 \\
$R^{2}(\mathrm{IP})$ & 0.82 & 0.76 \\
\hline
\end{tabular}
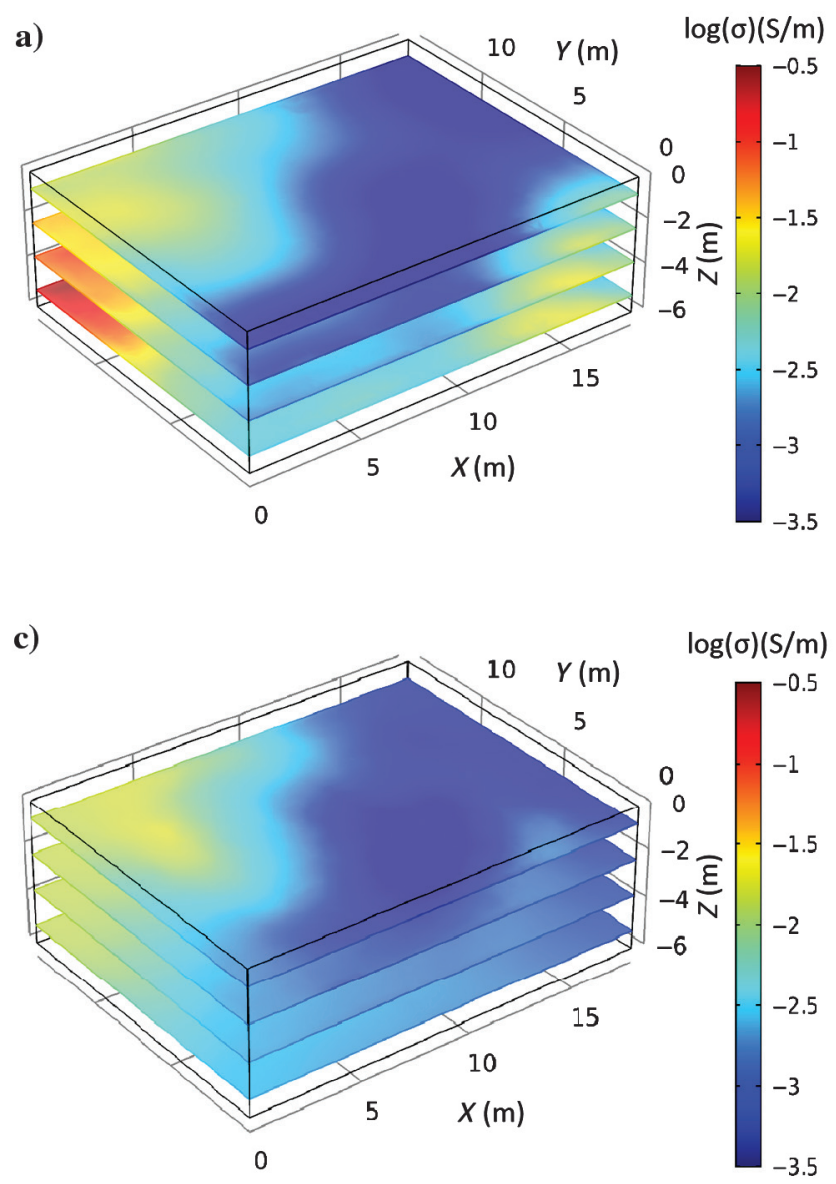

tions that one may encounter in the nature (see Figure 8a and 8b) Although being perfectly known, we assume during the inversion process that those true fields are unknown and we estimate them using our inverse code. This is an ideal means of testing the robustness of our inversion procedure before applying it to the real field data. For the sake of this test, we consider a simulation domain that covers a volume of $18 \times 14 \times 6 \mathrm{~m}$ and we consider six parallel electrodes profiles on top of this domain. The interspace between the profiles is $2 \mathrm{~m}$, and each profile contains 15 electrodes separated by $1 \mathrm{~m}$. Using a dipole-dipole configuration, we collect 372 apparent resistivity and 372 apparent chargeability data. To mimic the effect of noise sources, we artificially corrupt the data with a 5\% Gaussian white noise. In reality, under field conditions, the higher levels $n$ of a dipole-dipole survey are more affected by noise than the lower levels. The choice of a noise level with a constant voltage value could be more appropriate. In addition, the chargeability (extracted from the lower "off" signal) is more affected by noise than the resistivity (extracted from the larger "on" signal) considering a fixed noise level.

We set the initial conductivity and chargeability fields to be equal to the geometric means of the apparent conductivity and apparent chargeability, respectively. This is a reasonable choice for initial models because, in real field conditions, we only have access to the apparent parameters. Regardless, the inverse algorithm is not expected
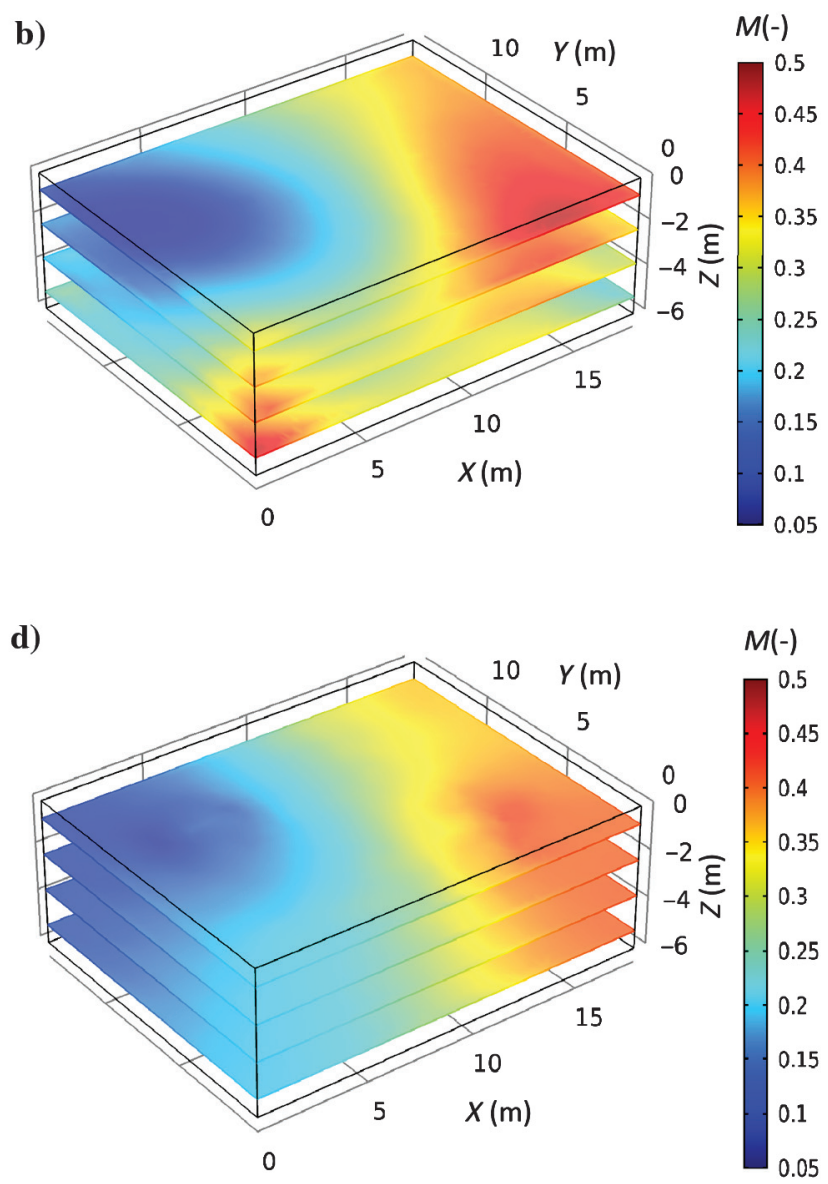

Figure 8. Benchmark test of the IP code with a synthetic model. (a) True conductivity distribution, (b) true chargeability distribution, (c) inverted conductivity distribution, and (d) inverted chargeability distribution. Note that some anomalies at the edge of the model are not well-resolved due to a lack of sensitivity in these regions. 
to be sensitive to the choice of the initial parameter models, and any realistic initial model should lead to convergence of the inverse problem or at least not be a cause of its divergence. Also, it is worth mentioning that as the parameters may span several order magnitudes and they have to be positive, it is better to recover the logarithms of these parameters, to enforce their positiveness in the inversion.

As stated before, the inversion is a two-step process: First, we invert the electrical conductivity, and then, we use this inverted conductivity as input for the inversion of the chargeability field. Although being more computationally intensive, this strategy performs better than the one in which the two fields are jointly inverted during each iteration. In this example, the resistivity and chargeability inversions converged after six iterations (see Figure 9). It can be seen from the convergence curves that the data misfits decrease in each iteration and finally reach the convergence criterion of an acceptable misfit value.
The reconstructed fields are shown in Figure $8 \mathrm{c}$ and $8 \mathrm{~d}$. The reconstructed fields are shown as a function of the true fields in Figure 10, and the convergence curves are shown in Figure 9. Figure 8c illustrates the reconstructed electrical conductivity field. We notice that the major features of the true conductivity fields are well-recovered in terms of shape and magnitude. Although we notice that a part of the low-conductivity anomaly in the corner appears to be oversmooth, this is due to the sensitivity of our electrodes configuration and is certainly not related to the inverse algorithm. A denser electrode configuration will improve the resolution of the tomography in this part of the simulation domain. The scatterplot of the true conductivity against the estimated one (see Figure 10) clearly exhibits a linear trend, proving that the major features of the true fields are very well-reconstructed. To quantify how close the inverted response is to the modeled response, the coefficient of determination $R^{2}$ is used.
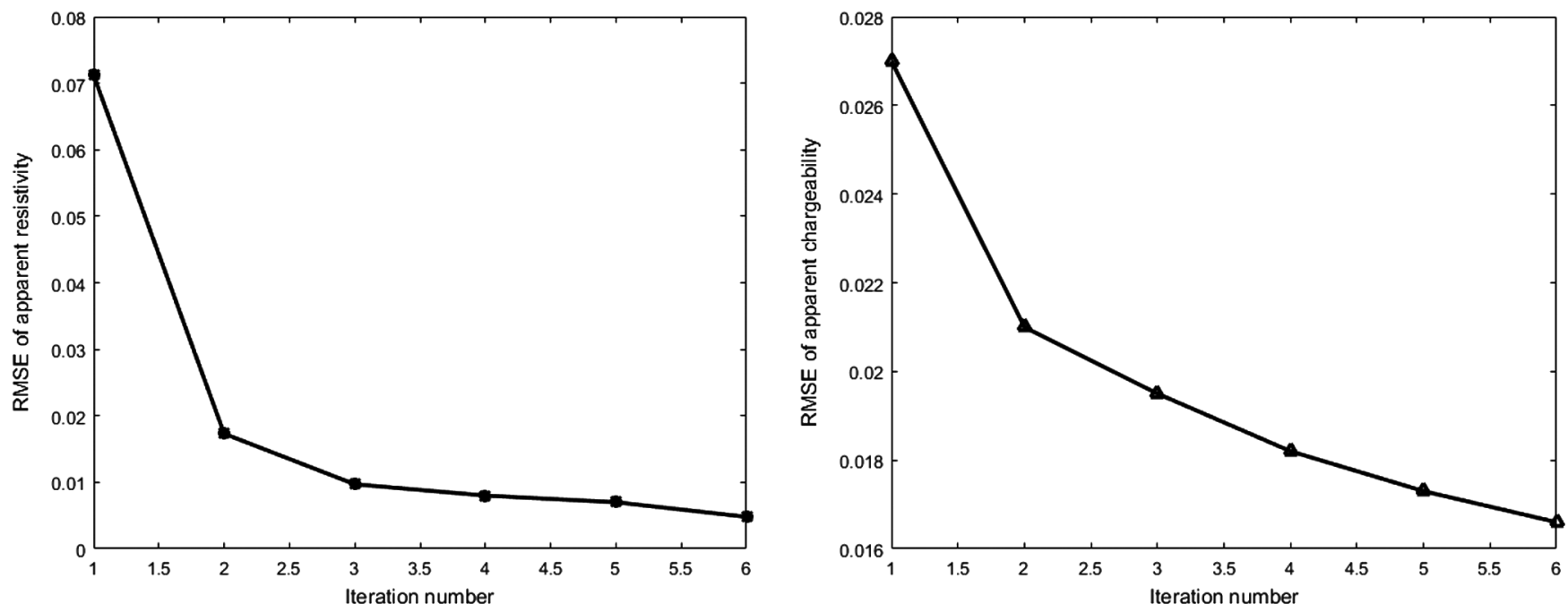

Figure 9. Data misfit versus the iteration number, the electrical resistivity tomography, and the chargeability tomography.
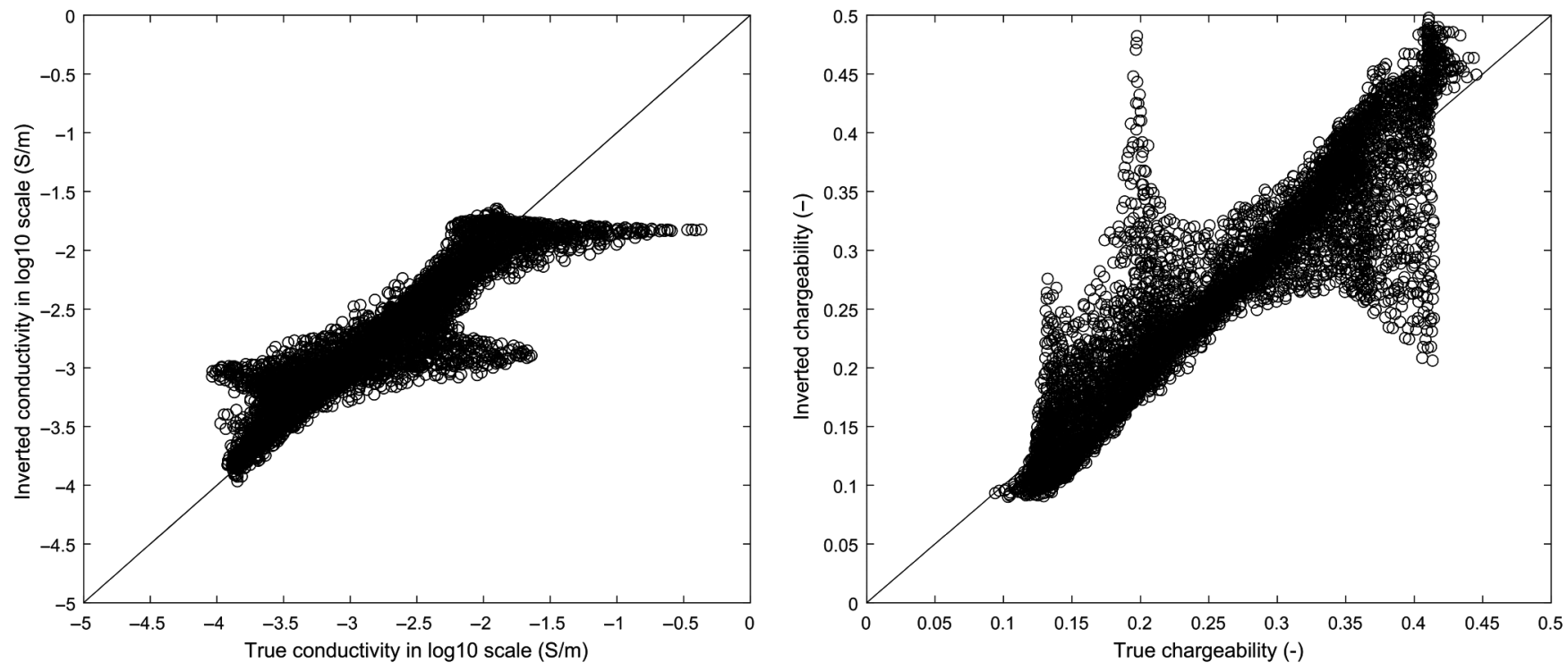

Figure 10. Inverted versus true conductivity and chargeability distributions for the benchmark test. 
$R^{2}$ measures how well the fit is with respect to the variation of the data as $R^{2}=1-S S_{\text {res }} / S S_{\text {tot }}$, where $S S_{\text {res }}$ denotes the sum of the squares of the difference between the modeled and the inverted responses (i.e., the residual sum of squares) and $S S_{\text {tot }}$ denotes the sum of the squared deviation from the mean of the modeled data themselves (i.e., the total sum of squares). The coefficient of determination $R^{2}$ value $(0.83$, Table 4$)$ is very high, confirming the good resolution of the estimated tomogram. In Figure 8d, we represent the tomogram of the inverted chargeability. As one can see through visual comparison, the spatial heterogeneities of the chargeability are well-reconstructed. In addition, the magnitudes of the principal anomalies are well-recovered and their spatial locations are well-retrieved. The chargeability $R^{2}$ is high (0.82, Table 4) and the plot of the true chargeabilities against the estimated ones also follows a linear trend (see Figure 10).

This benchmark test has demonstrated the ability of our inverse code to correctly reconstruct the electrical conductivity as well as the chargeability from noisy measured resistances and secondary voltage decay curves. The code can now be used for reconstructing the electrical conductivity and chargeability of our real field case study. This is accomplished in the next section.

\section{FIELD APPLICATION}

The field site of Grand Bois is located in the commune of SaintVincent sur L'Isle (France) $15 \mathrm{~km}$ away from the city of Périgueux. This archeological site corresponds to an old iron mining area, active from the 11th to the 15 th century, but it is poorly mentioned in the literature (see Bonnenfant, 2016). Its scale reveals a strategic importance for local seigniorial power. At this site, the slag overlies a siderolithic bedrock (Figure 11).

TDIP measurements were performed with a Syscal Pro from IRIS Instruments on a nearly $500 \mathrm{~m}^{2}$ field area, in May 2015 (Figure 12). A dipole-dipole survey comprising 21 profiles of 24 electrodes in each profile was performed. Along each profile, the spacing between the electrodes is $1 \mathrm{~m}$, which is also the distance between the profiles (Figures 12 and 13). We used salty water to reduce the contact resistance between the electrodes and the ground and to get the same order of magnitude of contact resistance for all electrodes (typically between 1 and $10 \mathrm{kohm}$ ). The injected current is of

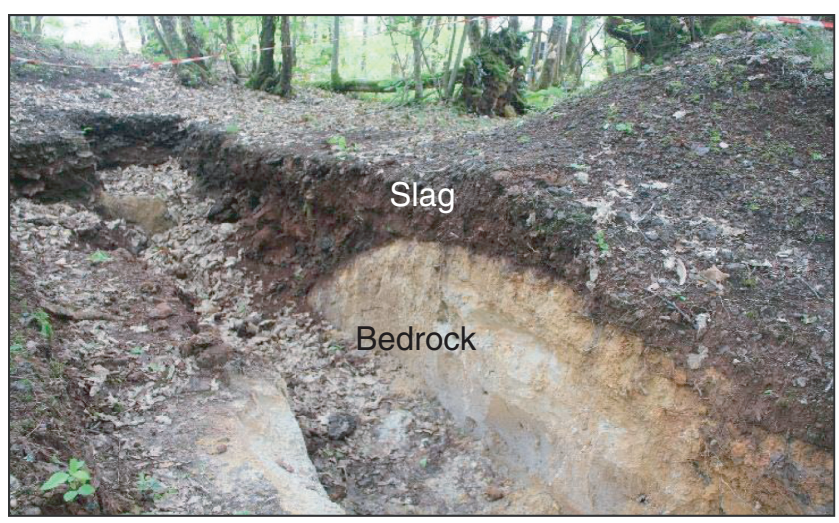

Figure 11. Structure of the slag heap with the slag overlying a siderolithic bedrock at a slag heap located at Saint-Vincent sur L'Isle test site in Dordogne (France). The GPS coordinates of the test site are longitude $0^{\circ} 53^{\prime} 17.9^{\prime \prime}$ and latitude $45^{\circ} 13^{\prime} 56.4^{\prime \prime}$. The ditch shown on the picture is located slightly north from the geophysical survey. the pseudocontinuous type in box mode $(+I, 0,-I, 0)$ with a period $T$ of $4 \mathrm{~s}$. The 20 partial chargeabilities were measured during the noninjection time $\left(T_{\text {off }}=1 \mathrm{~s}\right)$. The field area has a relatively flat topography (Figure 13a). The properties of the survey and inversion results are reported in Table 4. Examples of the apparent chargeability decaying curves are shown in Figure 14 displaying very good data quality.

The geometry and the finite-element mesh of our model are shown in Figure 13b, and topography is used in the modeling. Around the domain of interest, we use a coarse mesh to prescribe a zero potential to mimic infinity boundary conditions. The core domain is meshed with free tetrahedral meshes, and the mesh on the ground surface is denser to represent the topography characteristics and also to capture the surface electrical sensitivity close to the electrodes. Free tetrahedral elements are used in the domains surrounding the core domain for computational efficiency. The outermost layers are set as the infinite element domain boundaries to alleviate the finite effect. Swept meshes are constructed to the outermost layer domains for their better performance in the stretching of the infinite element boundaries. Finally, our model consists of 51,878 elements.

Conductivity inversion of the field data converges at the sixth iteration. $R^{2}=0.90$ is reached in our inversion, and the inverted conductivity slices and isosurface figures are shown in Figure 15a and 15c, respectively. Note that the conductivity is in $\log _{10}$ scale. From the inverted conductivity tomography, the slag heap is not well-detected. Indeed, the outcropping slags in the corner of the investigated field can hardly be seen in the conductivity tomogram.

The chargeability inversion of the field data converges at the ninth iteration. The data misfit is $R^{2}=0.76$, which is reached in our inversion of the field data, and the inverted chargeability slices and isosurface figures are shown in Figure $15 \mathrm{~b}$ and 15d, respectively. It is also noticeable that the slag heap is not just one block, but it is relatively scattered, although it is spatially confined in distinct volumes.

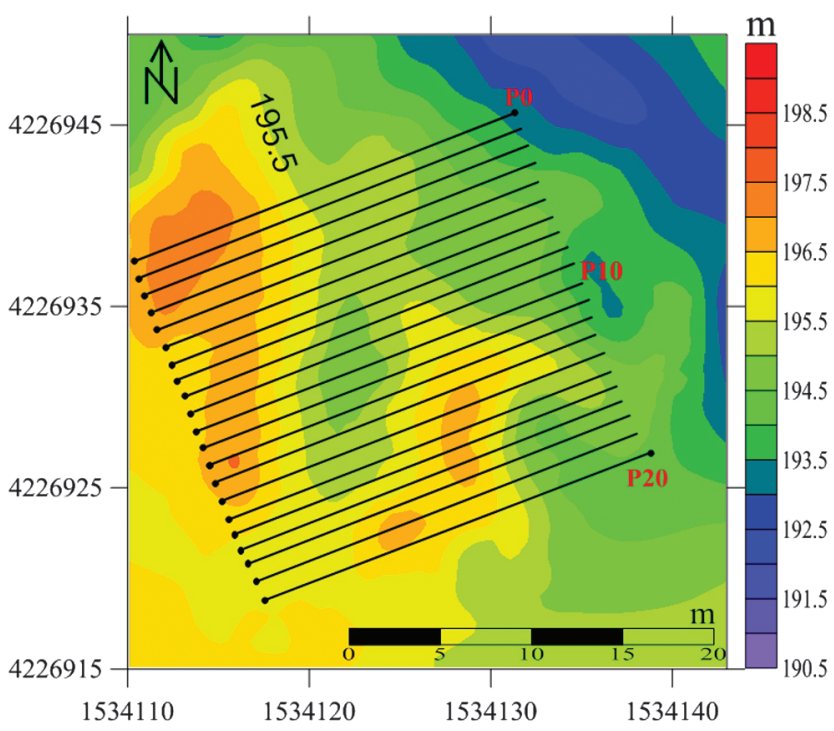

Figure 12. The 3D IP survey. The figure shows the localization of the 21 profiles ( 24 electrodes each). The color scale represents the topography of the area (altitude above sea level). The present survey comprises 3150 dipole-dipole measurements. 
Assuming that the background chargeability is negligible, we can derive the volumetric and the mass content of the slag heap as

$$
\varphi_{m}(x, y, z)=\frac{2}{9} M(x, y, z),
$$

where $M(x, y, z)$ is the inverted chargeability distribution and $\varphi_{m}(x, y, z)$ is the metallic volume fraction. The distribution of the metallic content is shown in Figure 16. The total metallic volume $V_{m}$ can be then computed by numerical integration

$$
V_{m}=\iiint_{\text {field }} \varphi_{m}(x, y, z) d x d y d z
$$

The total volume of metals is $86.3 \mathrm{~m}^{3}$. Because small chargeabilities are mostly caused by the background sands and soils, it is better to set a threshold for the chargeabilities when equations 16 and 17 are used (Florsch et al., 2012). Different than the sand that is used as the background material in the laboratory experiment, the background of the slag heaps in the field consists mainly of clay that is more polarizable than the sand. From the slices of the inverted chargeabilities, as shown in Figure 15b, the background represents the magnitude of chargeability at approximately 0.1 . Based on the isosurface patterns generated from different background chargeability threshold and the geologic information obtained from the field, 0.1 is found to be the most reasonable choice of background chargeability threshold. When 0.1 is chosen as the threshold and all the chargeabilities below this value are reset as zero, the total metallic volume is estimated to be $31.2 \mathrm{~m}^{3}$ (approximately $390 \mathrm{~m}^{3}$ of slag). The slags are shown to be iron rich. With the iron density of $7800 \mathrm{~kg} \mathrm{~m}^{-3}$, the residual mass of iron in this field is expected as 243.4 tons, which is not in itself an economically usable quantity. That said, our work was to provide a case study for the developed methodology and there are various heaps in the investigated area.
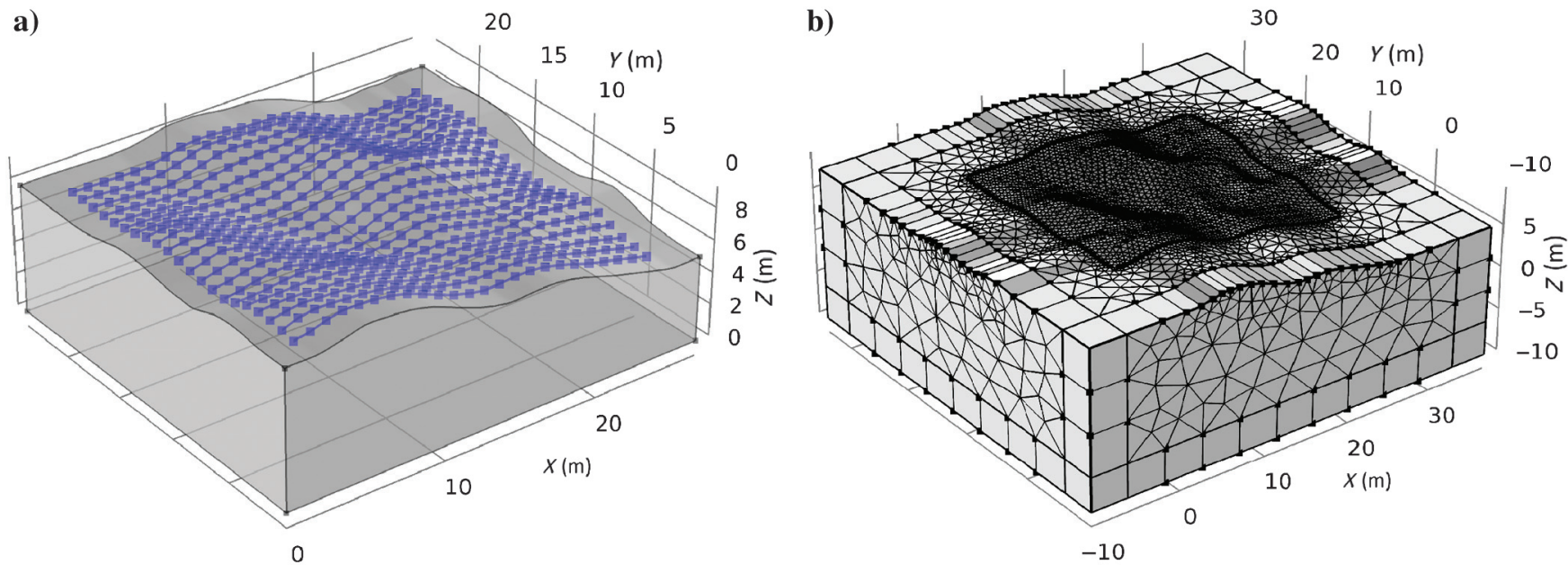

Figure 13. Topography and mesh of the investigated area. (a) Topography and measured electrode array (504 electrodes). (b) The forwardmodeling geometry of the field. The refined mesh is used for the core domain. Outside are the surrounding domains and the layers for the infinite element boundaries, where coarse meshes are used.
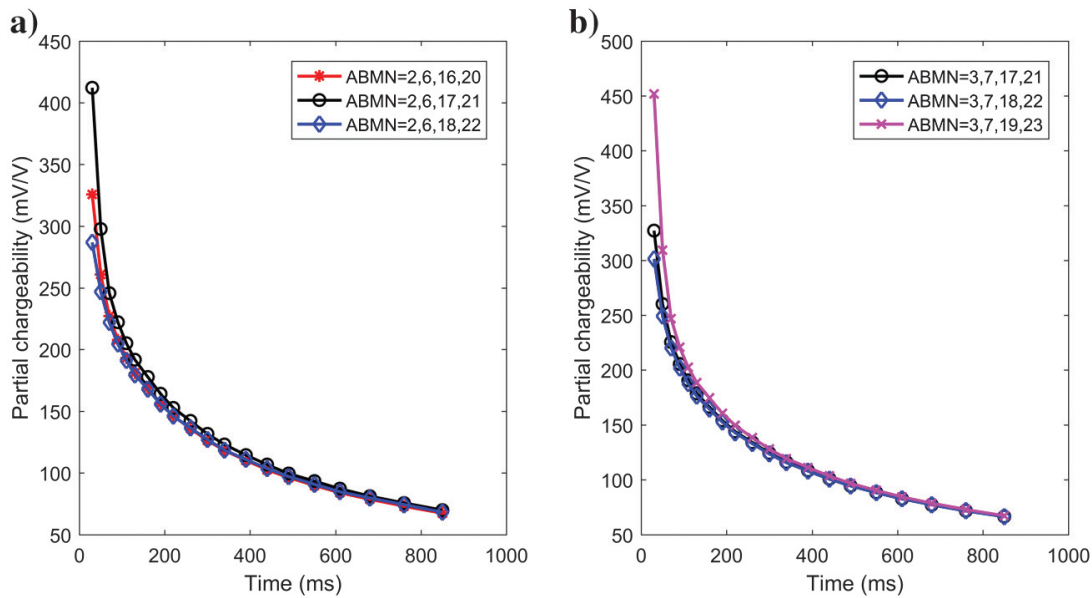

Figure 14. Partial chargeability (in $\mathrm{mV} / \mathrm{V}$ ) decaying curves (profile 1). The electrode numbers for the current electrodes $\mathrm{A}$ and $\mathrm{B}$ and the voltage electrodes $\mathrm{M}$ and $\mathrm{N}$ are provided in the figures. These curves indicate a clear polarization effect of the ground. 
a)

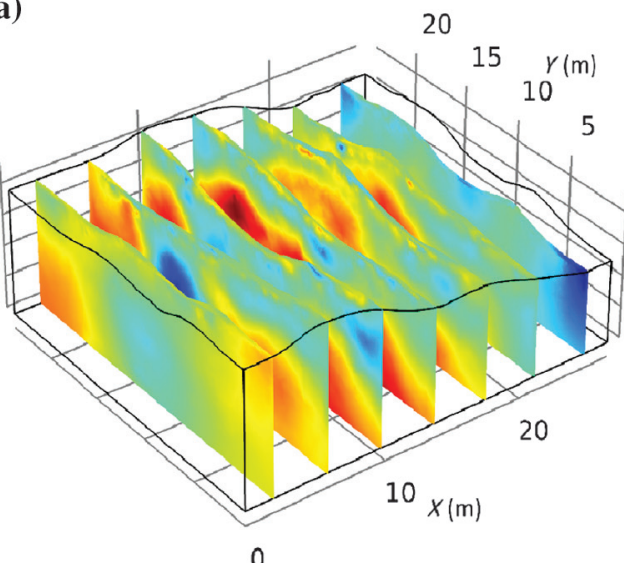

0

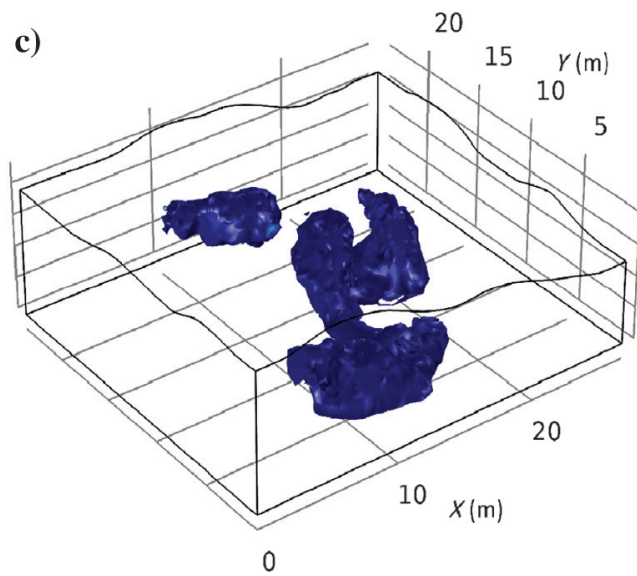

$\log (\sigma)(\mathrm{S} / \mathrm{m})$

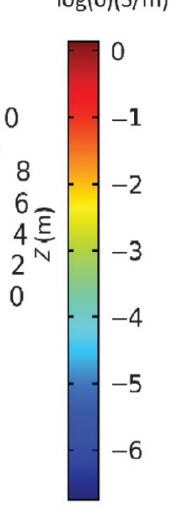

$\log (\sigma)(S / m)$
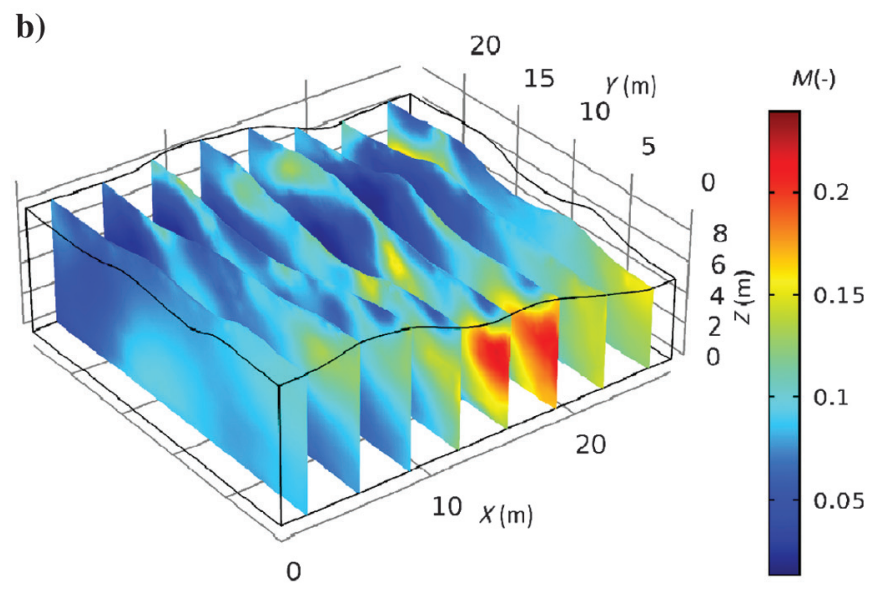

d)

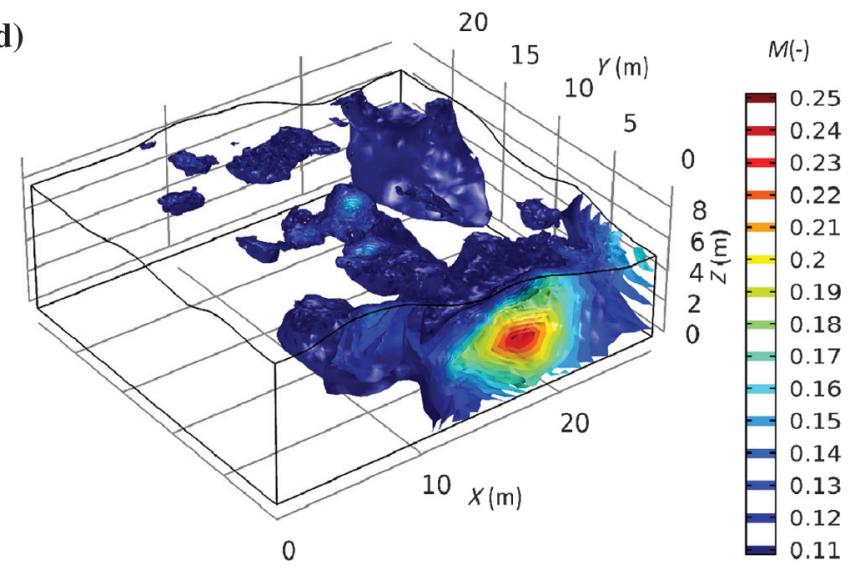

Figure 15. Tomography of the site of Saint-Vincent sur L'Isle (France). (a) Inverted conductivity. (b) Inverted chargeability. (c) Thresholded conductivity. (d) Thresholded chargeability between 0.10 and $0.25\left(100-250 \mathrm{mV} \mathrm{V}^{-1}\right)$. The shallow anomalies are consistent with the outcrops.

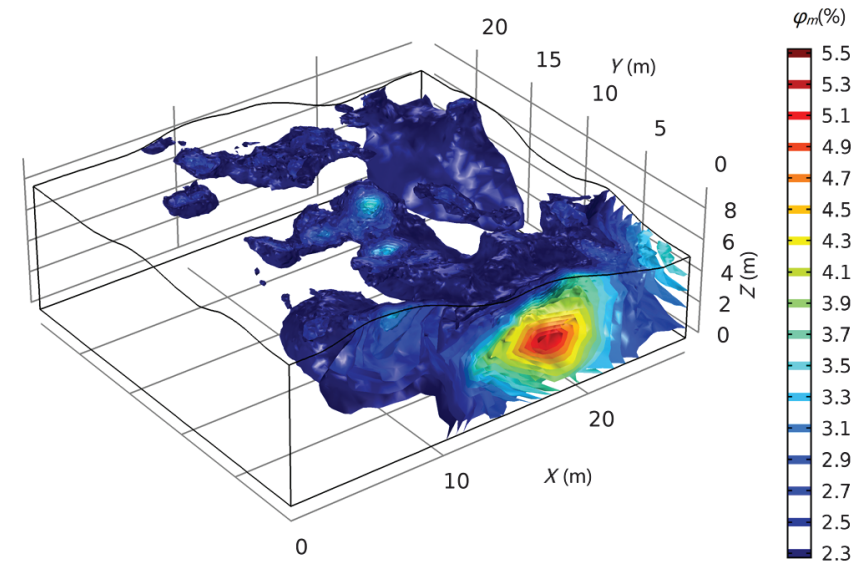

Figure 16. Volume fraction of metal in the heap using a threshold 0.1 for the background chargeability as validated by the theory.

\section{CONCLUSION}

To quantify the grade of slag heap deposits and the total amount of metal, we have proposed a method based on IP. The chargeability is related to the metal content by an equation determined from the effective medium theory. Laboratory experiments display a linear relationship between the chargeability and the volumetric content of slag in sandbox experiments. We derived a formula that can be used to calculate the grade of the slag from these data. Then, we applied our methodology on a field case study using a tomography algorithm based on the least-squares technique. A volume of high chargeability (above the background value of 0.10 ) indicates the position of the slag heap. The linear relationship between the chargeability and the metallic volumetric content is used to provide an image of the distribution (and total quantity) of metal present at this site. This study provides a field application of the theoretical relationships determined in the previous papers of this series.

\section{ACKNOWLEDGMENT}

We thank the Conseil Général de la Dordogne for his financial contribution to this study. We also thank the University of Melbourne through a project funded by the Commonwealth of Australia (contract CR-2016-UNIV.MELBOURNE-147672-UMR5275). We thank the associate editor, R. Mittet, A. Weller, and two anonymous referees for very constructive comments. 


\section{DATA AND MATERIALS AVAILABILITY}

Data associated with this research are available and can be obtained by contacting the corresponding author.

\section{APPENDIX A}

\section{CHARGEABILITY OF THE BACKGROUND}

We provide here a closed-form expression for the chargeability of the background (soil and slag matrix) based on the dynamic Stern layer proposed in our previous papers. The chargeability of the background $M_{b}$ is defined as the ratio between the normalized chargeability (in $\mathrm{S} \mathrm{m}^{-1}$ ) of the background $M_{n}^{b}$ and the instantaneous conductivity of the background $\sigma_{\infty}^{b}$ :

$$
\begin{gathered}
M_{b}=\frac{M_{n}^{b}}{\sigma_{\infty}^{b}}, \\
M_{n}^{b}=\sigma_{\infty}^{b}-\sigma_{0}^{b}=\sigma_{S}^{\infty}-\sigma_{S}^{0},
\end{gathered}
$$

where the quantities $\sigma_{S}^{\infty}$ and $\sigma_{S}^{0}$ denote the instantaneous and DC surface conductivity associated with electrical conduction in the electrical double layer coating the surface of the grains. To go further, we need a clear model for the polarization of the nonmetallic grains shown in Figure 2. According to the dynamic Stern layer model developed by Revil (2012, 2013a, 2013b), the normalized chargeability and instantaneous conductivity of the background material can be written as (Revil et al., 2017a)

$$
\begin{gathered}
M_{n}^{b}=\frac{1}{F \phi} s_{w}^{n} \rho_{g} \lambda \mathrm{CEC} \\
\sigma_{\infty}^{b}=\frac{1}{F} s_{w}^{n} \sigma_{w}+\frac{1}{F \phi} s_{w}^{n-1} \rho_{g} B \mathrm{CEC}
\end{gathered}
$$

where $\sigma_{w}$ (in $\mathrm{S} \mathrm{m}^{-1}$ ) denotes the pore-water conductivity, $\phi$ is the connected porosity (dimensionless), $s_{w}$ denotes the water saturation, $n$ is the second Archie's exponent (or saturation exponent), $F$ is (dimensionless) the intrinsic formation factor, $\rho_{g}$ is the grain density (in $\mathrm{kg} \mathrm{m}^{-3}$, typically $\rho_{g}=2650 \mathrm{~kg} \mathrm{~m}^{-3}$ for sedimentary rocks), and CEC denotes the cation exchange capacity (in $\mathrm{C} \mathrm{kg}^{-1}$ ) of the material. The last term of equation A-4 corresponds to the so-called surface conductivity, and $B$ denotes the apparent mobility of the counterions for surface conduction. This mobility is close to the mobility $B$ introduced by Waxman and Smits (1968) for the in-phase conductivity. The term $\lambda$ denotes the apparent mobility of the counterions for the polarization associated with the quadrature conductivity (for the quadrature conductivity, $\lambda$ is close to the apparent mobility introduced by Vinegar and Waxman, 1984). Note that the dimensionless number $R$ is also given by $R=\lambda / B=8 \times 10^{-2}$ (see Revil et al., 2017a). The quantities $\sigma_{w}, B$, and $\lambda$ have the same temperature dependence. This dimensionless number can also be defined as the ratio between the normalized chargeability and the surface conductivity. Finally, an expression of the chargeability of the background material can be obtained using equations A-1-A-4

$$
M_{b}=\frac{\rho_{g} \lambda \mathrm{CEC}}{\phi s_{w} \sigma_{w}+\rho_{g} B \mathrm{CEC}} .
$$

At low salinities, when surface conductivity dominates the porewater conductivity, we obtain the simplified result

$$
\lim _{\sigma_{w} \ll \frac{\rho_{g} B C E C}{\phi}} M_{b}=\frac{\lambda}{B}=R .
$$

This means that there is a universal value for the limit of the chargeability at low salinities, independent on saturation, salinity (in the low-salinity limit), and temperature.

\section{APPENDIX B DETERMINATION OF THE GRADE}

We consider that the grade $G$ (dimensionless) of the slag is defined as the mass fraction of metal in the slag; i.e.,

$$
G=\frac{m_{m}}{m_{\text {slag }}}=\frac{\rho_{m} V_{m}}{\rho_{\text {slag }} V_{\text {slag }}},
$$

where $m_{m}$ and $m_{\text {slag }}$ denote the mass of metal and the mass of slag in a representative elementary volume shown in Figure 1, respectively, $V_{m}$ and $V_{\text {slag }}$ denote the volume of metal and the volume of slag $\rho_{m}$ and $\rho_{\text {slag }}$ denote the mass density of the metal and the slag, respectively. According to Revil et al. (2015a, 2015b, 2017b, 2017c), the chargeability associated with the metallic particles can be written as

$$
M_{m}=\frac{9}{2} \varphi_{m}=\frac{9}{2} \frac{G \rho_{\text {slag }} V_{\text {slag }}}{\rho_{m}\left(V_{\text {soil }}+V_{\text {slag }}\right)},
$$

where $V_{\text {soil }}$ denotes the volume of soil in the representative volume. The mass fraction of slag in the representative elementary volume

$$
\varphi_{\text {slag }}^{m}=\frac{m_{\text {slag }}}{m_{\text {slag }}+m_{\text {soil }}}=\frac{\rho_{\text {slag }} V_{\text {slag }}}{\rho_{\text {slag }} V_{\text {slag }}+\rho_{\text {soil }} V_{\text {soil }}} .
$$

Combining equations B-2 and B-3, we have

$$
M_{m}=\frac{9}{2} \frac{G \varphi_{\text {slag }}^{m}\left(\rho_{\text {slag }} V_{\text {slag }}+\rho_{\text {soil }} V_{\text {soil }}\right)}{\rho_{m}\left(V_{\text {soil }}+V_{\text {slag }}\right)} .
$$

Introduce the volume fraction of slag

$$
\varphi_{\text {slag }}=\frac{V_{\text {slag }}}{V_{\text {slag }}+V_{\text {soil }}},
$$

yields

$$
M_{m}=\frac{9}{2}\left(\frac{G \varphi_{\text {slag }}^{m}}{\rho_{m}}\right)\left[\rho_{\text {slag }} \varphi_{\text {slag }}+\rho_{\text {soil }}\left(1-\varphi_{\text {slag }}\right)\right] .
$$

Introduce the volume fraction of slag. A relationship can be determined between the mass fraction and volume fraction of slag; see equations B-3 and B-5: 


$$
\varphi_{\text {slag }}^{m}=\frac{\rho_{\text {slag }} \varphi_{\text {slag }}}{\rho_{\text {slag }} \varphi_{\text {slag }}+\rho_{\text {soil }}\left(1-\varphi_{\text {slag }}\right)} .
$$

Finally, combining equations B-6 and B-7, we obtain

$$
M_{m}=\frac{9}{2}\left(\frac{G \rho_{\text {slag }}}{\rho_{m}}\right) \varphi_{\text {slag }} .
$$

\section{APPENDIX C}

\section{DOUBLE COLE-COLE PARAMETERIZATION}

Pelton et al. (1978) define the double Cole-Cole complex resistivity model by

$$
\begin{aligned}
& \rho *(\omega)=\rho_{0}\left[1-M_{1}\left(1-\frac{1}{1+\left(i \omega \tau_{1}\right)^{c_{1}}}\right)\right] \\
& \times\left[1-M_{2}\left(1-\frac{1}{1+\left(i \omega \tau_{2}\right)^{c_{2}}}\right)\right]
\end{aligned}
$$

where $\rho *=1 / \sigma *$ denotes the complex resistivity, $\rho_{0}$ denotes the DC resistivity (in $\Omega \mathrm{m}$ ), $M_{1}$ and $M_{2}$ are the chargeabilities, $c_{1}$ and $c_{2}$ are the two Cole-Cole exponents (dimensionless), $\tau_{1}$ and $\tau_{2}$ are the time constants (in s), and $\omega$ is the angular frequency. The indices 1 and 2 refer to lower and higher frequency dispersions, respectively. The first Cole-Cole model was traditionally used to represent the low-frequency dispersion and the other to represent either the EM coupling or the Maxwell-Wagner polarization process.

The SIP spectra discussed in the main text were inverted using this double Cole-Cole model and the nonlinear iterative method proposed by Mosegaard and Tarantola (1995), which is based on a MCMC sampling algorithm. The Bayesian approach describes the a priori information we have on the model vector, using a probability density $P(\mathbf{m})$, where $\mathbf{m}$ denotes the model vector of unknown parameters $\mathbf{m}=\left[\log \left(\rho_{0}\right) ; M_{1} ; c_{1} ; \log \left(\tau_{1}\right) ; M_{2} ; c_{2} ; \log \left(\tau_{2}\right)\right]$. Then, the algorithm combines this information with the observed data vector $\mathbf{d}_{\mathrm{obs}}$ and with the information provided by the double Cole-Cole model $L(\mathbf{m})$ as described in equation C-1. In Bayesian theory, the posterior probability density $\sigma(\mathbf{m})$ equals the prior probability density $P(\mathbf{m})$ times a likelihood function $L(\mathbf{m})$, which measures the fit between observed data and data predicted from the model $\mathbf{m}$; i.e.,

$$
\sigma(\mathbf{m})=k P(\mathbf{m}) L(\mathbf{m})
$$

where $k$ is a normalization constant. We describe the complex conductivity results by a vector of observed values $\mathbf{d}_{\mathrm{obs}}$ with Gaussian experimental uncertainties. We consider the case of independent, identically distributed Gaussian uncertainties. Then, the likelihood function describing the experimental uncertainties is given by

$$
L(\mathbf{m})=k \exp \left(-\frac{S(\mathbf{m})}{s^{2}}\right),
$$

where $s^{2}$ is the total noise variance and where

$$
S(\mathbf{m})=\frac{1}{2} \sum_{i=1}^{n}\left(g^{i}(\mathbf{m})-d_{\mathrm{obs}}^{i}\right)^{2}
$$

denotes the misfit function, $\mathbf{d}$ is the data vector, and $g(\mathbf{m})=\rho^{*}$ is the forward-modeling function. In this study, $s^{2}$ is the same for all data values. The acceptance probability for a perturbed model becomes in this case

$$
P_{\text {accept }}= \begin{cases}1 & \text { if } S\left(\mathbf{m}_{\text {new }}\right) \leq S\left(\mathbf{m}_{\text {old }}\right), \\ \exp \left(-\frac{\Delta S}{s^{2}}\right) & \text { if } S\left(\mathbf{m}_{\text {new }}\right)>S\left(\mathbf{m}_{\text {old }}\right),\end{cases}
$$

where $\Delta S=S\left(\mathbf{m}_{\text {new }}\right)-S\left(\mathbf{m}_{\text {old }}\right)$. The observed data used in the inversion process were the real and imaginary parts of the complex resistivity $\rho^{*}$ calculated from the amplitude and phase values measured at different frequencies. We assume that the standard deviation $s$ is equal to $10 \%$ of the measured complex resistivity values (i.e., corresponding to the maximum of the experimental error). Locally, uniform law (the probability distribution is constant over an interval $[\theta 1, \theta 2]$ and vanishes elsewhere) is used to describe the prior probability density on the model parameters. Interval ranges for the Cole-Cole model parameters are $\rho_{0}=[1 ; 1000] \Omega \mathrm{m}, M_{1}, M_{2}, c_{1}$, and $c_{2}$ have the same interval $[01], \tau_{1}=\left[10^{-5}, 10^{3}\right] \mathrm{s}$ and $\tau_{2}=\left[10^{-15}, 10^{1}\right] \mathrm{s}$. At the end of the inversion algorithm, we calculated the following root-meansquare (rms) error as the criterion to quantify the quality of the fit

$$
\mathrm{rms}^{2}=\frac{1}{n} \sum_{i=1}^{n}\left(\frac{g^{i}(\mathbf{m})-d_{\mathrm{obs}}^{i}}{d_{\mathrm{obs}}^{i}}\right)^{2},
$$

where $n$ denotes the number of measurements.

\section{REFERENCES}

Banks, D., P. L. Younger, R.-T. Arnesen, E. R. Iversen, and S. B. Banks, 1997, Mine-water chemistry: The good, the bad and the ugly: Environmental Geology, 32, 157-174, doi: 10.1007/s002540050204.

Beck, P., P. Braustein, and M. Philippe, 2008, Minières et ferriers du moyen âge en forêt d'Othe (Aube, Yonne): Approches historiques et archéologiques: Revue Archéologie de l'Est, 57, 333-365.

Bonnenfant, J., 2016, Les Grands-Bois (Saint Vincent-sur-1 Isle, Dordogne), Rapport de la campagne de fouille de 2015, Aquitaine Dordogne SaintVincent-sur-l'Isle, RFO, SRA Aquitaine, unpublished report.

Chen, J., A. Kemna, and S. S. Hubbard, 2008, A comparison between GaussNewton and Markov chain Monte Carlo based methods for inverting spectral induced polarization data for Cole-Cole parameters: Geophysics, $\mathbf{7 3}$, no. 6, F247-F259, doi: 10.1190/1.2976115.

Damgaard, A., and T. H. Christensen, 2011, Recycling of metals, in T. H. Christensen, ed., Solid waste technology and management: Blackwell Publishing Ltd., $1-2$.

Cole, K. S., and R. H. Cole, 1941, Dispersion and absorption in dielectrics: Journal of Chemical Physics, 9, 341-351, doi: 10.1063/1.1750906.

Cosenza, P., A. Ghorbani, N. Florsch, and A. Revil, 2007, Effects of drying on the low-frequency electrical properties of Tournemire argillites: Pure and Applied Geophysics, 164, 2043-2066, doi: 10.1007/s00024-007-0253-0.

Decombeix, P.-M., J.-M. Fabre, F. Tollon, and C. Domergue, 1998, Évaluation du volume des ferriers romains du domaine des Forges (Les Martys, Aude), de la masse de scories qu'ils renferment et de la production de fer correspondante: Revue d'Archéométrie, 22, 77-90.

Deutsch, C., and A. Journel, 1992, GSLIB: Geostatistical software library and user's guide: Oxford University Press.

Florsch, N., A. Feras, J. Bonnenfant, and C. Camerlynck, 2017, La polarisation provoquée, outil géophysique de spatialisation des amas de scories pour l'estimation des productions sidérurgiques (Induced polarization: A geophysical tool for slag characterization and ancient iron production assessment): Archeosciences, 41, 23-33, doi: 10.4000/archeosciences.

Florsch, N., M. Llubes, and F. Téreygeol, 2012, Induced polarization 3D tomography of an archaeological direct reduction slag heap: Near Surface Geophysics, 10, 567-574, doi: 10.3997/1873-0604.2012042.

Florsch, N., M. Llubes, F. Téreygeol, A. Ghorbani, and P. Roblet, 2011, Quantification of slag heap volumes and masses through the use of induced polarization: Application to the Castel-Minier site: Journal of Archaeological Science, 38, 438-451, doi: 10.1016/j.jas.2010.09.027.

Ghorbani, A., C. Camerlynck, N. Florsch, P. Cosenza, and A. Revil, 2007, Bayesian inference of the Cole-Cole parameters from time-and frequency- 
domain induced polarization: Geophysical Prospecting, 55, 589-605, doi: 10.1111/j.1365-2478.2007.00627.x.

Günther, T., and T. Martin, 2016, Spectral two-dimensional inversion of frequency-domain induced polarization data from a mining slag heap: Journal of Applied Geophysics, 135, 436-448, doi: 10.1016/j.jappgeo.2016.01.008.

Loke, M. H., and R. D. Barker, 1996, Rapid least-squares inversion of apparent resistivity pseudosections by a quasi-Newton method: Geophysical Prospecting, 44, 131-152, doi: 10.1111/j.1365-2478.1996.tb00142.x.

Mao, D., and A. Revil, 2016, Induced polarization response of porous media with metallic particles. Part 3: A new approach to time-domain induced polarization tomography: Geophysics, 81, no. 4, D345-D357, doi: 10 .1190/geo2015-0283.1.

Mao, D., A. Revil, and J. Hinton, 2016, Induced polarization response of porous media with metallic particles. Part 4: Detection of metallic and non-metallic targets in time domain induced polarization tomography: Geophysics, 81, no. 4, D359-D375, doi: 10.1190/geo2015-0480.1.

Marshall, D. J., and T. R. Madden, 1959, Induced polarization: A study of its causes: Geophysics, 24, 790-816, doi: 10.1190/1.1438659.

Meyer, C., B. Ullrich, and C. D. Barlieb, 2007, Archaeological questions and geophysical solutions: Ground-penetrating radar and induced polarization investigations in Munigua, Spain: Archaeological Prospection, 14, 202 212, doi: 10.1002/(ISSN)1099-0763.

Misra, S., C. Torres-Verdín, A. Revil, J. Rasmus, and D. Homan, 2016a, Interfacial polarization of disseminated conductive minerals in absence of redox-active species. Part 1: Mechanistic model and validation: Geophysics, 81, no. 2, E139-E157, doi: 10.1190/geo2015-0346.1.

Misra, S., C. Torres-Verdín, A. Revil, J. Rasmus, and D. Homan, 2016b, Interfacial polarization of disseminated conductive minerals in absence of redox-active species. Part 2: Effective complex conductivity and dielectric permittivity: Geophysics, 81, no. 2, E159-E176, doi: 10.1190/geo20150400.1

Mosegaard, K., and A. Tarantola, 1995, Monte Carlo sampling of solutions to inverse problems: Journal of Geophysical Research, 100, 12431-12447, doi: 10.1029/94JB03097.

Ogbonna, N., J. Petersen, and H. Laurie, 2006, An agglomerate scale mode for the heap bioleaching of chalcocite: The Journal of The South African Institute of Mining and Metallurgy, 106, 433-442.

Oldenburg, D. W., and Y. Li, 1994, Inversion of induced polarization data: Geophysics, 59, 1327-1341, doi: 10.1190/1.1443692.

Olhoeft, G. R., 1985, Low-frequency electrical properties: Geophysics, 50, 2492-2503, doi: $10.1190 / 1.1441880$

Ostrander, A. G., and K. L. Zonge, 1978, Complex resistivity measurements of sulfide-bearing synthetic rocks: Presented at the 48th Annual International Meeting, SEG, Expanded Abstracts.

Pelton, W. H., S. H. Ward, P. G. Hallof, W. R. Sill, and P. H. Nelson, 1978, Mineral discrimination and removal of inductive coupling with multifrequency IP: Geophysics, 43, 588-609, doi: 10.1190/1.1440839.

Revil, A., 2012, Spectral induced polarization of shaly sands: Influence of the electrical double layer: Water Resources Research, 48, W02517, doi: 10.1029/2011WR011260.

Revil, A., 2013a, Induced polarization response of porous media with metallic particles. Part 2: Comparison with a broad database of experimental data: Geophysics, 78, no. 4, D271-D291, doi: 10.1190/GEO2012-0503.1.

Revil, A., 2013b, Effective conductivity and permittivity of unsaturated porous materials in the frequency range $1 \mathrm{mHz}-1 \mathrm{GHz}$ : Water Resources Research, 49, 306-327, doi: 10.1029/2012WR012700.
Revil, A., A. Coperey, Z. Shao, N. Florsch, I. L. Fabricius, Y. Deng, J. R. Delsman, P. S. Pauw, M. Karaoulis, P. G. B. de Louw, E. S. van Baaren, W. Dabekaussen, A. Menkovic, and J. L. Gunnink, 2017a, Complex conductivity of soils: Water Resources Research, 53, 7121-7147, doi: 10.1002/wrcr.v53.8

Revil, A., G. Z. Abdel Aal, E. A. Atekwana, D. Mao, and N. Florsch, 2015b, Induced polarization response of porous media with metallic particles. Part 2: Comparison with a broad database of experimental data: Geophysics, 80, no. 5, D539-D552, doi: 10.1190/geo2014-0578.1.

Revil, A., N. Florsch, and D. Mao, 2015a, Induced polarization response of porous media with metallic particles. Part 1: A theory for disseminated semiconductors: Geophysics, 80, no. 5, D525-D538, doi: 10.1190/ geo2014-0577.1.

Revil, A., D. Mao, Z. Shao, M. F. Sleevi, and D. Wang, 2017b, Induced polarization response of porous media with metallic particles. Part 6: The case of metals and semi-metals: Geophysics, 82, no. 2, E97-E110, doi: 10.1190/ geo2016-0389.1.

Revil, A., M. F. Sleevi, and D. Mao, 2017c, Induced polarization response of porous media with metallic particles. Part 5: Influence of the background polarization: Geophysics, 82, no. 2, E77-E96, doi: 10.1190/geo2016-0388 1.

Seigel, H. O., 1959, Mathematical formulation and type curves for induced polarization: Geophysics, 24, 547-565, doi: 10.1190/1.1438625.

Ullrich, B., T. Günther, and C. Rücker, 2008, Electrical resistivity tomography methods for archaeological prospection, in A. Posluschny, $\mathrm{K}$. Lambers, and I. Herzog, eds., Layers of perception: Proceedings of the 35th International Conference on Computer Applications and Quantitative Methods in Archaeology (CAA), doi: 10.11588/propylaeumdok .00000488 .

Ullrich, B., C. Meyer, and A. Weller, 2007, Geoelektrik und georadar in der archäologischen Forschung: Geophysikalische 3D-untersuchungen in Munigua (Spanien), in G. A. Wagner, ed., Einführung in die Archäometrie: Springer, 76-93.

Vinegar, H. J., and M. H. Waxman 1984, Induced polarization of shaly sands: Geophysics, 49, 1267-1287, doi: 10.1190/1.1441755.

Waxman, M. H., and L. J. M. Smits, 1968, Electrical conductivities in oil-bearing shaly sands: SPE Journal, 8, 107-122, doi: 10.2118/1863-A

Weller, A., S. Brune, T. Hennig, and A. Kansy, 2000, Spectral induced polarization at a medieval smelting site: 6th EAGE/EEGS Meeting, Extended Abstracts, EL11, doi: 10.3997/2214-4609.201406182.

Wynn, J. C., A. E. Grosz, and V. M. Foscz, 1985, Induced polarization response of titanium-bearing placer deposits in the southeastern United States: U.S. Geological Survey open-file report, 85-756.

Yuval, W., and D. Oldenburg, 1997, Computation of Cole-Cole parameters from IP data: Geophysics, 62, 436-448, doi: 10.1190/1.1444154.

Zimmermann, E., J. Berwix, W. Glaas, H. Meier, H. M. Münch, and A. Kemna, 2007, ZEL-SIP04-V02: User manual: Forschungszentrum Julich $\mathrm{GmbH}$.

Zimmermann, E., A. Kemna, J. Berwix, W. Glaas, H. M. Münch, and J. A. Huisman, 2008, A high-accuracy impedance spectrometer for measuring sediments with low polarizability: Measurement Science and Technology, 19, 105603, doi: 10.1088/0957-0233/19/10/105603.

Zonge, K., and J. Wynn, 1975, Recent advances and applications in complex resistivity measurements: Geophysics, 40, 851-864, doi: 10.1190/1 .1440572 . 